\title{
LA CAÍDA DE LA INVERSIÓN EXTRANJERA AL FINAL DE LA SEGUNDA REPÚBLICA ESPAÑOLA ${ }^{1}$
}

\author{
Julio Tascón Fernández
}

\section{El encuadre histórico de la cuestión}

La Guerra Civil española fue un acontecimiento político de primer orden que produjo evidentes y dramáticas repercusiones en el interior e importantes efectos en el exterior. La victoria del general Franco -los nacionales- y la implantación de una dictadura de corte fascista contribuyeron a aumentar la fuerza de las potencias antidemocráticas en Europa.

Aparte del fenómeno político, la Guerra Civil alteró también la actividad económica en España y las relaciones económicas -comerciales- que mantenía con los países de su entorno. La Guerra Civil tuvo unos efectos destructivos sobre la economía porque no sólo alteró la normalidad política y social del país mientras duró el conflicto sino que la facción del ejército y de la sociedad civil que se rebeló contra el poder legítimo lo hizo para adueñarse del poder y aniquilar todo lo que el otro sector tenía y representaba. La facción rebelde no perseguía sólo la ocupación del poder sino también cambiar las bases sociales y políticas que lo sustentaban. Por lo tanto, la Guerra Civil española no puede entenderse plenamente sin tener en cuenta al mismo tiempo el intenso proceso de represión que se dio durante la guerra y en la posguerra sobre la población vencida y la creación desde el comienzo del conflicto de una nueva estructura de poder -el Nuevo Estado-, en el que el general Franco ostentaría todos los pode-

1. Este artículo es una versión revisada y algo modificada, que incluye unas reflexiones finales, del realizado con Glicerio Sánchez ReCio, «La agonía económico-financiera de la Segunda República española, 1936-1939. La caída de la inversión extranjera», en TAscóN Fernández, J. (ed.), La inversión extranjera en España, Madrid, Minerva, 2008, pp. 85116. 
res, los militares y los políticos, con lo que su régimen se orientaba en la órbita de las dictaduras fascistas. En este sentido los efectos destructivos de la Guerra Civil sobre la economía española iban más allá de los ocasionados por la guerra y el paréntesis de anormalidad política y social.

La Guerra Civil dividió el país en dos zonas. La legalidad estaba sólo en una de ellas, por lo que las empresas con intereses extranjeros establecidas en España pudieron seguir operando, aunque sometidas a unas condiciones que alteraban su funcionamiento normal: la prioridad de todos los elementos relacionados con la guerra, tanto en el frente como en la retaguardia; el establecimiento de un «comité internacional de no-intervención», en el que, en contra de toda evidencia, a la par de calificar la guerra como un asunto interno, daba carta de naturaleza a la facción rebelde, reconociéndola de hecho y asumiendo las decisiones políticas y las actividades económicas que realizara; la reducción de las reservas de divisas en el Banco de España y la pérdida de valor de la divisa española y de la producción ante un conflicto tan largo y de difícil solución²; y por último, el riesgo económico que suponía invertir en España en aquellas circunstancias.

La relación económica con el exterior llevada a cabo en la zona franquista se realizó bajo otros parámetros, desempeñando una función primordial los gobiernos de los respectivos países y el del general Franco, para lo que se crearon compañías mercantiles especializadas para efectuar este tipo de intercambios en Alemania, Italia... ${ }^{3}$ En términos generales, podría decirse que se produjo un pro-

2. Ángel Viñas en su reciente libro La soledad de la República (2006, pp. 25 y ss.) ha tratado ampliamente de todas estas cuestiones.

3. La imposibilidad de llevar a cabo acuerdos de clearing («liquidación de deudas por compensación») en aquellas circunstancias con el Gobierno de Burgos condujo al famoso caso del sistema de la HISMA-ROWAK mencionado ya por Ángel ViÑAs, La Alemania nazi y el 18 de Julio, antecedentes de la intervención alemana en la guerra civil española, Madrid, Alianza Editorial, 1976 (1. ${ }^{a}$ ed. en 1974), p. 7: HISMA es la abreviatura del nombre comercial de la Hispano-Marroquí de Transportes, Sociedad Limitada (registrada en Tetuán, 31/07/1936, bajo el nombre de Carranza y Bernhardt, Transportes en general, sería más conocida como HISMA); ROWAK fue fundada en octubre de 1936 y Göring fue el responsable de asignarle el cometido de la completa organización comercial, incluyendo el sistema especial de clearing entre Alemania y el territorio de los nacionales. Para ello también resultaría decisiva la conexión portuguesa a través de Nicolás Franco, nombrado embajador de su hermano en Lisboa, pues el canal portugués fue profusamente utilizado en las transacciones de la Alemania nazi con la España de Franco. Con la ROWAK se arreglaba la financiación del comercio con la España rebelde de manera oficiosa pues oficialmente no era posible. Ver también Viñas et al., (1979, pp. 160 y 162-170). Ver también Christian LeiTz (1996, p. 85), quien señala cómo HISMA se queda sin su influyente papel durante 1939, pero ROWAK continuaría desempeñando un papel central en la relación entre la Alemania nazi y la España de Franco hasta el final de la Segunda Guerra Mundial. Con idénticos fines a los de la HISMA funcionó la Sociedad Anónima Financiera Nacional Italiana (SAFNI), que menciona TAMAmES (1981, p. 249). 
ceso de paralización y retroceso de los intercambios económicos con el exterior en la zona republicana durante la Guerra Civil, y otro de apertura y consolidación en la zona franquista, sobre todo a partir de febrero de 1937, cuando se incorporaron a ésta territorios de alto valor económico y estratégico.

Los créditos contraídos por el Gobierno de Franco y reconocidos por ley Reservada de Jefatura del Estado de 1939 son transacciones financieras que testimonian la dinámica asimétrica de la internacionalización del conflicto. Es de sobra conocido el abierto apoyo de Estado prestado por las potencias fascistas y el tipo de ayudas, más o menos encubiertas, que Francia y otros países occidentales otorgaron a la República. La política de «no intervención» cuenta desde agosto de 1936 con un comité en Londres que representó durante toda la guerra una mera farsa. Es sabido también que dicha política lastró los esfuerzos republicanos por conseguir armas y material bélico ${ }^{4}$.

Los préstamos internacionales se pueden considerar como un tipo de comercio internacional conocido como comercio intertemporal ${ }^{5}$. La inhibición de las potencias democráticas occidentales para apoyar a la República de forma resuelta tiene que ver, desde la óptica del referido comercio, con las escasas o nulas expectativas que se le suponían a la República de producir y consumir en el futuro. Se desconocen datos fiables que permitan cuantificar el volumen de la ayuda financiera exterior, aparte de los créditos soviéticos, recibida por la República ${ }^{6}$.

En este marco histórico adquieren todo su significado los datos del «Informe sobre la situación financiera, comercial, agrícola e industrial de la España republicana durante 1936-1938», elaborado a principios de 1938, en el que se recoge el impacto de la guerra sobre los intercambios económicos con el exterior, tomando como referencia los efectuados en toda España en el primer semestre de 1936 y comparándolos con la evolución que siguieron en el segundo semestre del mismo año y en el primero de 1937 en la zona republicana ${ }^{7}$. Se ha de reconocer que los datos aportados por este documento -con las «garantías» de

4. Ángel Viñas afirma que «La no intervención oficializó la farsa». Ver Viñas (1984, p. 27) y también Viñas (2006, pp. 45 y ss.).

5 Ver Krugman, Paul R. y Obstreld, Maurice, Economía Internacional. Teoría y Política, Madrid, McGraw-Hill, 1993, 2. ${ }^{a}$ ed., p. 184.

6. Dicha ayuda obviamente hubo de materializarse, como afirma Viñas, en divisas o productos de diferente naturaleza. Ver Viñas (1984, p. 176) y también Viñas (2007, pp. 369 y ss.).

7. El documento se encuentra en FO, 371, 22670. La carátula del documento muestra que su procedencia es la Secretaría Comercial de la Embajada Británica y que se redactó en febrero de 1938, en su sede de Caldetas, Barcelona. El «informe sobre la situación financiera, comercial, agrícola e industrial de la España republicana durante 1936-1938» es, como apostilla la indicación situada debajo del índice, el «informe económico del Sr. Juliá». 
la Secretaría Comercial de la Embajada Británica- suponen un paso importante en el conocimiento de la economía española, que constituyó otro elemento fundamental, aunque no suficientemente resaltado, de la Guerra Civil. ${ }^{8}$

La secuencia de nuestra exposición de los hechos comienza incidiendo en el panorama del comercio exterior, para seguir con el de la inversión extranjera. La evolución de ambos corre pareja y confirma la consabida agonía económica de la Segunda República española. El comercio exterior disminuye gravemente desde el comienzo de la Guerra Civil, en lo que ya era una tendencia apuntada en los años precedentes (Viñas, 1979, 125-140; Tena, 1992, 48-54; Prados, 2003, 483) y como era de esperar la inversión extranjera sigue los pasos de ese pronunciado declive.

\section{La situación económica republicana durante la Guerra Civil}

La posición de España, antes de la Guerra Civil, para realizar las importaciones solicitadas por el funcionamiento de la actividad económica, era deficitaria respecto al exterior, pues las exportaciones de mercancías sólo financiaban una parte de los pagos corrientes al extranjero. La diferencia se cubría con algunas entradas netas por cuenta corriente (remesas de emigrantes y fletes) y con entradas netas de capital extranjero, ya fuesen inversiones directas o financieras. La dependencia del exterior parece crítica, como muestran las cifras de la balanza de pagos y que se concretan en un déficit acumulado durante el período 19311934 en la balanza comercial de 326,43 millones de dólares9. La característica de un déficit persistente en la balanza comercial es típica de la mayoría de países en vías de desarrollo, como era precisamente el caso de España en vísperas de la guerra de 1936.

8. La extrema dificultad de hallar información coetánea de algún tipo de entidad u organismo que confiera cierto grado de oficialidad administrativa a los datos económicos de la época, había llevado a Ângel Viñas (1979, p. 235) a titular el epígrafe de su Política comercial exterior... referido a la España nacional: «Un comercio exterior desconocido en cifras», debido a lo fragmentario de las estadísticas comerciales que su equipo pudo localizar. Por otra parte los documentos que preceden el informe económico del Sr. Juliá y el mismo autor puntualizan una crítica de la información contenida y una valoración de las fuentes empleadas, para que se tomen las debidas cautelas. Ver FO, 371, 22670, dentro del Informe, notas preliminares.

9 Las entradas netas por servicios y transferencias durante dicho período fueron de 147,22 millones de dólares. El saldo neto de la balanza de capitales fue de 134,1 millones de dólares, que incluye tanto los de largo como los de corto plazo. Ver Chamorro, S. y Morales, T., «Las balanzas de pagos de Francisco Jáinaga», Información Comercial Española, 154 (1976), pp. 107-118. Citado en Catalán, 1995, p. 207. 
Según afirma Ángel Viñas, se desconocen los resultados de la exportación republicana durante el conflicto bélico ${ }^{10}$. En 1938 la Guerra Civil española había retrocedido en la atención internacional y además la evidencia dejada por la reacción franco-británica de distanciamiento, respecto a la posición de la República, permitieron un pronóstico claro. La República había carecido de un margen de maniobra exterior ${ }^{11}$. Con los siguientes datos del comercio exterior español relativos a 1936 y primer semestre de 1937, referidos tanto a toda España como al territorio republicano, se comprende mejor el retraimiento occidental para prestar al Gobierno legal de la nación española. Se suele prestar a quien tiene ya dinero y también a quien tiene posibilidades de obtenerlo. La información del comercio exterior, en miles de pesetas oro, como cabía esperar, para todos los artículos considerados, no generaría muchas expectativas halagüeñas al inversor extranjero. Estos datos son una primicia que nos brinda el «Informe sobre la situación financiera, comercial, agrícola e industrial de la España republicana durante 1936-1938». Dicho informe fue preparado por don Joaquín Juliá (con la ayuda de Mr. Malcolm), único superviviente de la Secretaría Comercial de la Embajada Británica con sede en Caldetas, Barcelona ${ }^{12}$.

Las potencias cuya preeminencia dentro del comercio exterior republicano, durante 1936 y primer trimestre de 1937, parece indiscutible son Gran Bretaña, Francia, Estados Unidos, Alemania,... Por encima de todas ellas destacan las exportaciones de la República a Gran Bretaña, que supera en 30 millones de pesetas oro las respectivas importaciones. El detalle de unas compras inglesas con gran repercusión en un saldo de la balanza comercial favorable al territorio republicano, puede verse en el siguiente cuadro.

Cuadro 1. Comercio hispano-británico, 1936-1937. (En miles de pesetas oro)

\begin{tabular}{|c|c|c|c|c|c|}
\hline \multicolumn{3}{|c|}{ IMPORTACIÓN } & \multicolumn{3}{c|}{ EXPORTACIÓN } \\
\hline Toda España & \multicolumn{2}{|c|}{ Territorio Republicano } & Toda España & \multicolumn{2}{c|}{ Territorio Republicano } \\
\hline $\begin{array}{c}1 \text { semestre, } \\
1936\end{array}$ & 2 semestre, & 1 semestre, & 1 semestre, & 2 semestre, & 1 semestre, \\
1936 & 1937 & 1936 & 1936 & 1937 \\
\hline 9.090 & 2.940 & 4.643 & 6.174 & 3.817 & 2.956 \\
\hline 78 & 14 & 15 & 4.871 & 3.124 & 2.845 \\
\hline
\end{tabular}

10. VIÑAS, 1984, p. 176.

11. ViñAS, 1984, p. 35. Para percatarse de dicho margen no hay que esperar y dar crédito a la comunicación del comisario del pueblo soviético para las finanzas, de 1 de agosto de 1938, de que sólo existía a disposición de la República poco menos de tonelada y media de fino. Ver también Viñas, 1984, p. 174.

12. Véase FO, 371, 22670, fol. 291. 


\begin{tabular}{|c|c|c|c|c|c|}
\hline 1.136 & 145 & 6 & 651 & 640 & 349 \\
\hline 4.980 & 984 & 347 & 1.545 & 2.896 & 5.923 \\
\hline 11.981 & 3.085 & 527 & 8 & 10 & 12 \\
\hline 3.157 & 929 & 1.085 & 1.837 & 877 & 1.106 \\
\hline 983 & 405 & 478 & 47 & 15 & 2 \\
\hline 597 & 161 & 4 & 77 & 18 & \\
\hline 377 & 147 & 138 & 22 & 24 & 1 \\
\hline 1.000 & 136 & 47 & 65 & 140 & 212 \\
\hline 381 & 37 & & 246 & 368 & 825 \\
\hline 1.710 & 744 & 2.281 & 57.400 & 29.008 & 37.139 \\
\hline 1.229 & 219 & 896 & 105 & 45 & 5 \\
\hline 77 & 40 & & & & \\
\hline 36.787 & 9.989 & 10.569 & 73.093 & 40.996 & 51.377 \\
\hline & & & 36.306 & 31.007 & 40.808 \\
\hline & & & 66,5 & 80 & 83 \\
\hline
\end{tabular}

Fuente: FO, 371, 22.670.

El Reino Unido compra, en su comercio con España, productos por valor del 83\% del intercambio total entre ambos países. Sin embargo España que, según convenios anteriores, debería adquirir en el Reino Unido productos y artículos por valor del 80\% de las compras que aquél haga en España, sólo adquiere el $17 \%$ del citado intercambio comercial. Inglaterra adquiere en proporciones crecientes productos alimenticios, metales, minerales, corcho, productos químicos y, cosa extraña, las industrias españolas exportan ahora lanas y sedas a Gran Bretaña ${ }^{13}$. Los comentarios sugeridos al redactor del Informe por el siguiente cuadro, dimanan de su mera observación.

13. Según afirma el señor Juliá, resulta bastante paradójico que después de las enconadas batallas reñidas por las industrias textiles inglesas en otros tiempos para retener el mercado español, ahora éstas contemplen indiferentes cómo lo pierden por completo, además de ver cómo sus homólogas españolas exportan lanas y sedas al Reino Unido. El señor Juliá sugiere que la situación actual es digna de estudio y «debería prestársele la atención que merece por parte de las Cámaras de Comercio y de la Federación de Industrias Británicas». Véase FO, 371, 22670, fol. 354. 
Cuadro 2. Resúmenes semestrales del comercio de España con varios países, 1936-1937 (En miles de pesetas oro)

\begin{tabular}{|c|c|c|c|c|c|c|}
\cline { 2 - 7 } \multicolumn{1}{c|}{} & \multicolumn{4}{c|}{ IMPORTACIÓN } & \multicolumn{3}{c|}{ EXPORTACIÓN } \\
\cline { 2 - 7 } & Toda España & \multicolumn{2}{c|}{ Territorio Republicano } & Toda España & \multicolumn{2}{c|}{ Territorio Republicano } \\
\hline Países & $\begin{array}{c}1 \text { semestre, } \\
1936\end{array}$ & $\begin{array}{c}2 \text { semestre, } \\
1936\end{array}$ & $\begin{array}{c}1 \text { semestre, } \\
1937\end{array}$ & $\begin{array}{c}1 \text { semestre, } \\
1936\end{array}$ & $\begin{array}{c}2 \text { semestre, } \\
1936\end{array}$ & 1 semestre, \\
\hline Alemania & 50.811 & 15.899 & 1.206 & 52.169 & 7.995 & 194 \\
\hline Estados Unidos & 72.397 & 18.096 & 7.830 & 26.937 & 8.916 & 5.939 \\
\hline Francia & 28.214 & 9.832 & 12.351 & 51.142 & 15.538 & 34.161 \\
\hline Gran Bretaña & 36.787 & 9.989 & 10.569 & 73.094 & 40.996 & 51.377 \\
\hline Argentina & 17.954 & 10.961 & 13.009 & 10.989 & 4.456 & 2.566 \\
\hline Bélgica & 11.540 & 4.789 & 8.700 & 18.530 & 7.715 & 11.332 \\
\hline Egipto & 11.843 & 11.819 & 152 & 656 & 449 & 286 \\
\hline Suecia & 10.669 & 2.497 & 952 & 5.610 & 1.445 & 2.822 \\
\hline Suiza & 8.116 & 1.610 & 795 & 6.149 & 4.306 & 3.726 \\
\hline Rusia & 2.861 & 1.716 & 11.671 & 185 & 3 & 5.170 \\
\hline Todos los países & 381.581 & 124.122 & 96.184 & 331.619 & 122.184 & 140.456 \\
\hline
\end{tabular}

Fuente: FO, 371, 22.670.

Alemania pierde su privilegiada posición en el comercio con el territorio gubernamental, lo cual resulta lógico debido a su actitud favorable a los nacionalistas. Sólo vende algunos minerales, maquinaria y productos químicos y se limita a comprar algunos alimentos. Los Estados Unidos sufren también un aparente retroceso en sus ventas a la España oficial. Éstas quedan reducidas a aceites minerales, productos químicos y comestibles, mientras que compran sólo algunos comestibles, corcho y metales. Aunque directa o indirectamente llegaron a España materiales de guerra, aviones y camiones fabricados en los Estados Unidos, en cantidad de importancia, pero que no constan en las estadísticas. Francia recupera el terreno perdido gracias a su vecindad y le vende alimentos, metales, automóviles, productos químicos y manufacturas de lana, al tiempo que compra alimentos y corcho. Inglaterra vende a España carbón, comestibles, productos químicos, caucho y algún vehículo y le compra el 35 por ciento de todos los comestibles y bebidas que exporta la España republicana, buena cantidad de metales y minerales, corcho y productos químicos. No cabe duda de que es la nación que más le ayuda a resolver su problema monetario ${ }^{14}$. La coyuntura descrita por

14. FO, 371, 22670, fols. 354-355.

Pasado y Memoria. Revista de Historia Contemporánea, 8, 2009, pp. 35-73 
las cifras que suministra el informe del Sr. Juliá resulta coherente, para el caso de las principales potencias económicas, como Estados Unidos y Gran Bretaña, con las cifras de Ruiz Morales $(1945,79)$ o con las suministradas por los empleados del Overseas Department del Banco de Inglaterra. ${ }^{15}$

Argentina vende grandes cantidades de cereales y carnes congeladas y le compra manufacturas de algodón y vinos. Egipto pierde por completo el mercado español para sus algodones y se limita a comprarle algunos géneros de punto. Bélgica vende a España cereales y azúcar, vehículos, productos químicos y lanas y compra gran cantidad de comestibles. Suecia también sufre las consecuencias del bloqueo y sólo vende pulpa para fabricar papel y algo de maquinaria y se limita a comprar frutas españolas. La URSS aprovecha la oportunidad y vende a España gasolina y algodón, productos químicos y comestibles y le compra comestibles y metales (véase el siguiente cuadro) ${ }^{16}$.

Cuadro 3. Comercio exterior español, 1936-1937 (En miles de pesetas oro)

\begin{tabular}{|c|c|c|c|c|c|c|}
\cline { 2 - 7 } \multicolumn{1}{c|}{} & \multicolumn{4}{c|}{ IMPORTACIÓN } & \multicolumn{3}{c|}{ EXPORTACIÓN } \\
\cline { 2 - 7 } & Toda España & \multicolumn{2}{c|}{ Territorio Republicano } & Toda España & \multicolumn{2}{c|}{ Territorio Republicano } \\
\hline \multirow{2}{*}{ Artículos } & $\begin{array}{c}1 \text { semestre, } \\
1936\end{array}$ & $\begin{array}{c}2 \text { semestre, } \\
1936\end{array}$ & $\begin{array}{c}1 \text { semestre, } \\
1937\end{array}$ & $\begin{array}{c}1 \text { semestre, } \\
1936\end{array}$ & $\begin{array}{c}2 \text { semestre, } \\
1936\end{array}$ & $\begin{array}{c}1 \text { semestre, } \\
1937\end{array}$ \\
\hline Minerales & 48.606 & 13.845 & 19.294 & 23.115 & 6.006 & 3.596 \\
\hline Madera & 12.326 & 3.680 & 533 & 14.945 & 9.464 & 9.506 \\
\hline Animales & 11.908 & 3.226 & 1.248 & 11.528 & 4.345 & 2.207 \\
\hline Metales & 23.285 & 6.487 & 3.913 & 15.342 & 7.102 & 9.973 \\
\hline Maquinaria & 64.010 & 20.808 & 3.470 & 1.607 & 807 & 286 \\
\hline Prod. químicos & 56.223 & 12.769 & 7.876 & 14.606 & 6.019 & 3.491 \\
\hline Papel & 12.845 & 2.984 & 1.322 & 4.116 & 3.109 & 1.271 \\
\hline Algodón & 52.184 & 27.304 & 3.292 & 7.362 & 4.886 & 1.974 \\
\hline Cáñamo, yute & 9.621 & 2.770 & 1.661 & 2.258 & 615 & 106 \\
\hline Lana & 5.045 & 927 & 1.302 & 4.165 & 877 & 1.052 \\
\hline Seda & 7.217 & 723 & 152 & 956 & 1.191 & 1.199 \\
\hline Alimentos & 51.944 & 20.553 & 49.062 & 230.823 & 77.315 & 105.643 \\
\hline Varios & 12.073 & 3.241 & 2.001 & 753 & 444 & 150 \\
\hline
\end{tabular}

15. Ver BEA, OV 61/3, s/f.

16. Don Joaquín Juliá dice no haber incluido a Italia en la relación porque su comercio con España había sido desplazado en 1936 por las sanciones con motivo de la campaña en Abisinia y «hoy se puede decir que no existe ninguna relación comercial entre ambos países». Ver FO, 371, 22670, fol. 355. 


\begin{tabular}{|c|c|c|c|c|c|c|}
\hline Tabaco & 14.255 & 4.802 & 1.058 & 38 & & \\
\hline Totales & 381.581 & 124.122 & 96.184 & 331.619 & 122.184 & 140.456 \\
\hline
\end{tabular}

Fuente: FO, 371, 22.670.

La división adoptada en 13 clases de productos es la correspondiente al arancel de aduanas español. Las cifras utilizadas en el informe del señor Juliá son consideradas, después de su examen crítico, como el «punto de referencia más seguro ${ }^{17}$. Al señor Juliá le merecen esa calificación a pesar de reconocer a dichas cifras oficiales, relativas al comercio exterior de la España republicana, la posibilidad de «estar sujetas a márgenes de error considerables» ${ }^{18}$. Los períodos con datos son el primer semestre de 1936 que comprende el último período pacífico, en el que, según afirma Juliá, se incubó la tempestad debido principalmente a la política desastrosa del gobierno Lerroux-Gil Robles y a la osadía del Presidente de la República en colaboración con Portela Valladares. El segundo semestre de 1936 no parece muy recomendable para ser estudiado con seriedad. Sin embargo, el primer semestre de 1937, «cuando el Gobierno ya trasladado a Valencia y fuera de la acción directa de la guerra, comienza a prestar atención a reorganizar la retaguardia, los despachos oficiales comienzan a funcionar con relativa tranquilidad y las estadísticas se aproximan bastante a la realidad».Sin olvidar, por supuesto, que «pasaron antes por el tamiz de la censura» ${ }^{19}$. A la vista del cuadro anterior (Comercio Exterior español, 1936-1937), parece evidente el colapso de las importaciones, no obstante las de productos alimenticios resultan casi tan altas para el territorio republicano como en tiempos normales para toda España. «Lo que continúa importándose es absolutamente indispensable para la vida nacional $»^{20}$.

La posición de Suiza respecto al territorio republicano, donde parece tener la mayoría de sus intereses, arroja un saldo acreedor para el primer semestre de 1936, que se convierte en deudor contra Suiza en cuanto empieza la guerra, pues importa bastante más que exporta. Al parecer Suiza envía quesos, productos químicos y sedas hacia España, y compra alimentos y corcho. En la España republicana toda la parte financiera del comercio exterior español está concentrada exclusivamente en el Banco Exterior de España, que es el único que

17. Juliá realiza, a lo largo de todo su informe, una exhaustiva crítica de las fuentes utilizadas. Ver, por ejemplo: FO, 371, 22670, fol. 346.

18. FO, 371, 22670, fol. 346 .

19. FO, 371, 22670, fol. 347 .

20. FO, 371, 22670, fol. 347 .

Pasado y Memoria. Revista de Historia Contemporánea, 8, 2009, pp. 35-73 
puede hacerse cargo de los pagos de mercancías importadas y del cobro de las exportadas ${ }^{21}$. Dentro del peso específico que detenta el comercio exterior de la República con Suiza, no parecen demasiado relevantes ni los pagos en divisas de las exportaciones, ni cualquier transferencia financiera para afrontar el pago de las reducidas importaciones. Pero las apariencias engañan y ésta es, indudablemente, una de esas ocasiones donde lo más importante es lo que no se ve, lo oculto detrás de las cifras oficiales. Ello se debe a que el Gobierno republicano no hace figurar en las estadísticas -para no facilitar pruebas al Comité de No Intervención-el material de guerra que importa ${ }^{22}$.

Un informe del Banco de Inglaterra fechado el 16 de septiembre afirma que el Gobierno español está gastando dinero, o mejor dicho, el dinero del Banco de España, como si fuera agua y desde que empezó la revolución, ha sido vendido entre unos $£ 15$ millones y $£ 20$ millones. Los primeros envíos fueron realizados vendiendo el oro al Banco de Francia ${ }^{23}$. Pero últimamente los envíos han sido hechos desde Barcelona por orden del Gobierno catalán y para eludir cualquier complicación política el Banco de Francia ha rechazado tocar el oro. Los agentes del Gobierno español han sido desde el principio del Chase Bank. Los motivos de este proceder radican en que todas las compras de materiales de guerra están realizadas en nombre del Gobierno mexicano ${ }^{24}$. El Chase Bank estaba muy unido a México, cuyas cuentas representaban un determinado alcance de los intereses mexicanos en plata y, por consiguiente, era normal para ellos encargarse de arreglos financieros entre los gobiernos español y mexicano. Pero lo más notable de toda la operación es que «the bulk of the war materials are being purchased in Belgium and Switzerland $»^{25}$.

21. Al Centro de Contratación de Moneda se le han reducido considerablemente sus anteriores facultades, pues hoy quien ordena y manda y quien ejecuta al mismo tiempo, es la Dirección General del Tesoro, o mejor dicho, el propio ministro de Hacienda, señor Negrín. Ver FO, 371. 22670, fol. 353.

22. «Como tampoco hace constar el valor de las joyas y el oro exportado para hacer frente a los pagos de obligaciones contraídas por las Subsecretarías de guerra, municiones, aire, marina y abastecimientos». FO, 371, 22670, fol. 346.

23. Los departamentos oficiales (Subsecretarías de Guerra, Marina, Aire, Armamentos y las Direcciones Generales de Abastos, Industria y Agricultura) utilizan en París una oficina que se llama Campsa-Gentibus, que dispone del oro que le envía el Gobierno directamente y también del que le proporciona la «Banque Commercialle pour l'Europe du Nord», entidad soviética que hace avances a cuenta del oro, joyas y objetos de arte depositados en Rusia. Véase FO, 371, 22670, fol. 352.

24. La administración Cárdenas obraba en defensa del Gobierno republicano y por ello Roosevelt, después de algunas indecisiones, decreta, a principios de 1937, el embargo de material de guerra con destino a España. Véase VIÑAS, 1984, p. 23.

25. Véase BEA, OV61/2, vols. 3, 4 y 5 (2169/4), p. 121ª. 
Cuando la guerra terminó, ya en agosto de 1940, sabemos que se firmaron acuerdos de trueque con países como Japón, para intercambiar potasio y mercurio por seda en bruto, camfor y mentol, con Holanda naranjas por café, azúcar y goma, con Bélgica naranjas por bienes manufacturados. Ahora el trato con Suiza es más idílico y agrario, se cambian naranjas por vacas lecheras ${ }^{26}$. Para esas fechas ya hacía tiempo que dada la política adoptada por la República, respecto a la parte financiera del comercio exterior español, se había eliminado a los antiguos comerciantes e industriales, a los exportadores españoles y a los compradores extranjeros y los pocos que subsistieron tuvieron que someterse a las exigencias de comisiones extraordinarias para los representantes de los comités revolucionarios y para el Gobierno ${ }^{27}$. También es cierto que para 1938 la cotización de la divisa republicana, el billete rojo de 100 pesetas, agotaba sus últimos segundos en Berna ${ }^{28}$.

Los préstamos financieros que pudieron suponer un comercio intertemporal en relación con el comercio exterior español republicano, poca importancia pudieron tener, dejando a un lado la participación rusa. Desde 1938 en adelante ya no pudieron tener ninguna relevancia. Por ahora no parece que el caso de Suiza se salga de esta norma general. Si hablamos de deudas contraídas en el comercio exterior, debemos mencionar los acuerdos de clearing que se arbitran ya desde antes de la contienda, como paliativo para hacer frente a las mismas y

26. Véase BEA, OV61/4, (2170/2), Spain, v. 10-15, fol. 32. Informe del Overseas \& Foreign Department, 9/agosto/1940.

27. Éstas son las conclusiones del señor Juliá después de haber analizado minuciosamente los mecanismos del sistema de permisos imperantes en el territorio republicano. Ver FO, 371, 22670 , fols. 350-353.

28. Véase el siguiente cuadro:

Billete rojo de 100 pesetas. Cotización en francos suizos

\begin{tabular}{|l|c|c|c|c|}
\cline { 2 - 5 } \multicolumn{1}{c|}{} & \multicolumn{4}{c|}{ Media Mensual } \\
\cline { 2 - 5 } \multicolumn{1}{c|}{} & 1936 & 1937 & 1938 & 1939 \\
\hline Enero & & 16,88 & 4,69 & 0,44 \\
\hline Febrero & & 13,94 & 3,85 & \\
\hline Marzo & & 11,49 & 3,63 & \\
\hline Abril & & 15,37 & 3,37 & \\
\hline Mayo & & 13,83 & 2,58 & \\
\hline Junio & & 12,32 & 2,92 & \\
\hline Julio & 41,87 & 8,71 & 2,79 & \\
\hline Agosto & 39,27 & 8,60 & 1,23 & \\
\hline Septiembre & $(-) 30,68$ & 7,74 & 1,44 & \\
\hline Octubre & 30,74 & 7,60 & 1,38 & \\
\hline Noviembre & 24,44 & 5,99 & 0,75 & \\
\hline Diciembre & 16,47 & 5,19 & & \\
\hline
\end{tabular}

Fuente: Ministerio de Trabajo, Boletín de Estadística, n. ${ }^{\circ} 4$ (octubre-diciembre), 1939, p. 46.

(-) Día 27; devaluación del franco suizo en un 30 por ciento. 
los consecuentes estrangulamientos inducidos en el vaivén de importaciones y exportaciones.

Los años precedentes a la Guerra Civil son testigo de la necesidad de llegar a acuerdos bilaterales donde se negocian las modalidades de pagos. En España se había mantenido un elevado nivel de importaciones que mermó considerablemente sus divisas y provocó la regulación de las mismas, a través del Centro Oficial de Control Monetario (COCM $)^{29}$. Entre las referidas modalidades de pagos se encuentran las cuentas «clearing» que ya se habían acordado entre Alemania y España. Los suizos pretendieron iniciar una de esas cuentas con España, para dar agilidad al problema del pago de divisas ${ }^{30}$, puesto que en 1935 las sumas adeudadas y no pagadas por las dificultades en la obtención de divisas se elevaban a 15 millones de francos suizos ${ }^{31}$.

La política de contingentación suiza unida a las sumas adeudadas por los importadores españoles a la Confederación (los 15 millones de francos) conllevó un descenso de las exportaciones suizas a España. El plan del ministro Chapaprieta para sanear la situación financiera del COCM fracasa, entre otras cosas, porque el sucesor en la cartera de Hacienda, Rico Avellano, no consuma la operación ${ }^{32}$. Los suizos veían un acuerdo de clearing con España, según Beatriz Sánchez, como el único medio posible (dejando aparte un acuerdo de compensación) de cobrar sus deudas pendientes que en agosto de 1935 lo eran, principalmente, en concepto de suministro de mercancías de tránsito y licencias de energía eléctrica, además de otros costes ${ }^{33}$. Pero la Guerra Civil truncó toda esperanza a la industria de exportación suiza de lograr unas relaciones comerciales normales con España ${ }^{34}$.

29. La mayor parte de las naciones sostuvieron durante esos años medidas de bloqueos de saldos, lo cual también obliga a realizar varios acuerdos bilaterales. Véase SÁnchez FerNÁNDEZ, Beatriz, Proteccionismo y liberalismo. Las relaciones comerciales entre Suiza y España: 1869-1935, Frankfurt, Vervuest Verlag, 1996, p. 186.

30. Véase BA, 7110: 117, Eggar an Meienberg \& Co., 4 August 1935. Cit. Sánchez, Beatriz, 1996, p. 186.

31. La suma se elevaría a 20 millones de tener en cuenta la deuda en otras monedas.

32. Véase SÁnchez, Beatriz, 1996, p. 189.

33. La suma del adeudo era de 8.997.102 francos suizos, 7.527 .863 pesetas, 116.224 francos franceses, 2.996 libras esterlinas y 262 dólares, a los cuales se debe sumar, dentro de los costes secundarios, en el tránsito de las mercancías (franqueos, provisiones, salarios), 126.000 francos y 800 pesetas. Para más detalles véase SánchEz, Beatriz, 1996, p. 189.

34. Acuerdo de clearing en 1940. Commission Nationale pour la publication de documents diplomatiques suisses, préparé à l'Institut d'Histoire de l'École polytechnique fédérale de Zurich par Jean-François Bergier et André JäGgi avec la collaboration de Marc PerRenoud, Documents Diplomatiques Suisses.Diplomaische Dokumente der Schweiz, Documenti Diplomatici Svizzeri, 1848-1945, volume 13 (1939-1940), ler. janvier 1939-31 décembre 1940, Bern, Benteli Verlag, 1991. 
A pesar de todo, como afirma don Joaquín Juliá en su informe de 1938, gran parte del resultado de la contienda que está destruyendo al pueblo español depende de la posibilidad del Gobierno de continuar abasteciéndose del extranjero. «Está demostrado que, ni de material de guerra, ni de combustibles, ni de víveres para los combatientes y para la población civil, puede el territorio ocupado por las fuerzas del Gobierno ser abastecido por la producción nacional. La destrucción de los depósitos de gasolina de Tarragona y Valencia ha creado al Gobierno una situación difícil y si se repitiera el hecho en Alicante y Barcelona, revestiría caracteres de catástrofe. Algo parecido sucede con el carbón y en cuanto a alimentos, cada día son más caros y resulta más difícil encontrar comida ni donde comer. Las carreteras catalanas fronterizas a Francia están siempre invadidas por grandes camiones que traen de todo cuanto necesita el Gobierno, pero con ser mucho, no es suficiente para las enormes necesidades de toda la España republicana. Es necesario para el Gobierno mantener libres las comunicaciones marítimas, pero que sea solo la marina inglesa la que se dedique a este tráfico puede resultar expuesto a serios contratiempos internacionales.

Desde el punto de vista británico, si el Gobierno, en defensa de su tradicional política de la libertad de los mares, tolera que los buques mercantes ingleses lleguen con víveres y combustibles a los puertos dominados por el Gobierno de la República y los protege deliberadamente, como sucedió en el mar Cantábrico, le prestaría una ayuda directa al Gobierno dejando en entredicho el principio de no intervención. Y por otra parte, si el Gobierno de Su Majestad prohíbe a los buques mercantes con bandera británica acercarse a las costas del Mediterráneo, en poder del Gobierno de la República favorece directamente la causa de los nacionalistas, cosa que constituye otra forma de intervención $»^{35}$.

Las siguientes palabras acerca de la ayuda financiera que necesitaría España, cuando la guerra hubiera acabado, nos sirven para matizar la idea del panorama que se dibujaba ya en abril de 1938 con toda nitidez y donde la posición suiza en materia de préstamos financieros se relega a un segundo plano.

«There is no doubt that after the civil war, Spain will be badly in need of financial help; and that Spain will turn to London as the most likely lender. Altought the financial rehabilitation and reconstruction of the country may be considered a matter for international action, the only other potential lender on a large scale appears to be the U.S.A. who in this case would not be hampered by the Jhonson Act. But political opinion there is definitely anti-Franco. Other

35. El señor Juliá termina con la siguiente reflexión: «Tal vez fuese oportuno estudiar desapasionadamente qué le conviene hacer a Inglaterra, ante una situación que resulta difícil complacer a unos y a otros». Caldetas, 23 de febrero de 1938. Véase FO, 371, 22670, fols. 355-356. 
possibilities, on a smaller scale are Holland, Switzerland and Sweden. France can probably be ruled out for political reasons. A "League" reconstruction scheme is out of the question $»^{36}$.

\section{La relación entre el comercio exterior y la inversión extranjera}

El planteamiento histórico económico que desarrollamos aquí se basa en la agonía comercial de la Segunda República que implicaría un declive de la inversión extranjera, sobremanera de la inversión directa, con alguna excepción entre los países líderes de la época. El declinar de la inversión directa extranjera que corroboran los datos del comercio exterior y viceversa constituye una suerte de pescadilla que se muerde la cola. Ante la carencia de una información de la Balanza de Pagos ${ }^{37}$, para comprobar la evolución del capital a largo plazo, utilizamos algunas fuentes elaboradas en aquellos años por experimentados coetáneos, entre los que se cuenta con la división Overseas de los empleados del Bank of England, y un informe muy completo elaborado desde la Embajada del Reino Unido sita en Caldetas, Barcelona. Otros materiales complementarios aportan datos para contrastar con los obtenidos hasta ahora, bien provenientes de «back projections», o aportados desde testimonios de la época, como los de origen alemán ya utilizados por Ángel Viñas y sus colaboradores (1979). El informe de la Embajada británica se puede considerar un homólogo, en territorio republicano, del informe de la Embajada alemana, también terminado en 1938, «Bericht über die Wirtschaftslage im Nationalen Spanien» y utilizado por Viñas $(1979,199)$. En lo que respecta al comercio exterior de 1935 a 1938 y para ambas zonas como un todo, según la información estadística de los socios más importantes, Viñas (1979, 242 y ss.) utiliza como fuente: «Das Spanische Aussenhandel». ${ }^{38}$

Con la información disponible la valoración del decrecimiento de la inversión extranjera afectaría, en primera instancia, a la España republicana y también a la zona nacional cuya victoria en la contienda, cuando terminaba el año 1938, era lo más probable para los observadores extranjeros que aún tenían sus intereses en la Península.

36. BEA, 0V61/3, vols. 6, 7, 8 y 9 (2170/1), Borrowing by Spain, 24/April/ 1938, p. 66.

37. Ya lo señalaba entre otros Albert CARReras $(1989,548)$ : «La precisión de nuestras estadísticas de balanza de pagos está muy alejada de lo ideal hasta finales de la década de los años cincuenta...». Lo que reitera problemas apuntados ya en las afirmaciones de Valentín Andrés Álvarez sobre la inexistencia de datos fidedignos de comercio exterior antes de 1930. El argumento de la sobrevaloración de las importaciones debido a los intereses proteccionistas de industriales y comerciantes sobre todo catalanes estaba en su tesis doctoral y es algo conocido.

38 El documento está tomado por Viñas de los Archivos Militares Alemanes Freiburg: AMAF, legajo R 88/v 1001, y en él están basados los cuadros de las páginas 242, 244, 245-247. 
Las cifras inéditas de los cuadros construidos por don Joaquín Juliá (1938), que se han mostrado en este estudio, constituyen sobre todo un aporte de información de la propia época. Esos datos cuentan con el aval de la justificación autocrítica de su autor, así como con la valoración ponderada de colaboradores de la división Overseas del Bank of England. La inexistencia de este tipo de informaciones sobre el comercio exterior ha llevado a su estimación por algunos autores que las reconstruyen, a partir de los datos disponibles. ${ }^{39}$ Esperamos que esta modesta aportación contribuya a contrastar y corroborar algo más la evidencia de un decadente comercio exterior y el inevitable corolario de la consiguiente caída en la inversión extranjera en España.

El cuadro de la inversión extranjera existente entre 1936 y 1939 sirve esencialmente para enmarcar y resaltar la firme implantación de la inversión directa norteamericana que, habiendo crecido notablemente desde 1929, también acusa recibo del paso de la guerra ${ }^{40}$. El cuadro permite observar la información para poder compararla -en dólares constantes-, aunque existen ciertas dificultades que provienen de lo incompleto de la fuente para 1936 (Tascón, 2003, 284-286), así como la ausencia de datos para un caso relevante como el suizo, en 1939. Para pasar los dólares de las diferentes inversiones extranjeras de 1936 a dólares de 1939 y así poder compararlos hemos utilizado el deflactor del GDP ${ }^{41}$. El intento de identificar los principales intereses extranjeros en la industria y el comercio españoles de 1936 carece de la precisión estadística deseada por los empleados del departamento Overseas del Banco de Inglaterra, pero se aduce la imposibilidad de realizarlo a partir de las fuentes oficiales. De hecho los empleados añaden un conjunto de observaciones -cuya procedencia es «el conocimiento particular y la observación personal»- con la intención de subsanar errores y carencias ${ }^{42}$.

39. Véase Tena (1992), Prados (2003) y Martínez Ruiz (2005). Especialmente la reconstrucción del cuadro III.5 de las cifras oficiales y estimadas del comercio exterior español (19361939) elaborado por TENA $(1992,56)$.

40. La inversión norteamericana estaba implantada en el país desde el siglo XIX (Teresa ToRTELLA, 2000), pero con gran fiabilidad tenemos constancia cuantitativa de su evolución desde que el US Department of Commerce empieza a elaborar sus censos sobre la inversión extranjera americana, por motivos fiscales, en 1929.

41. El GDP (Gross Domestic Product) es el equivalente a nuestro PIB (Producto Interior Bruto). Parece lo más apropiado según las explicaciones de Officer y Williamson (2007), que así lo aconsejan cuando se trata del coste histórico de oportunidad de inversiones.

42. Existen errores que los empleados del Banco intentan subsanar con anotaciones a lápiz, pero se hacen indicaciones como la de M. McGrath en carta dirigida a Wilson Smith, que permiten subsanar algunas omisiones. McGrath (5-11-1936) hace alusión a los intereses belgas que no se mencionan y según él son considerables. También indica cómo en el Memorando no se entra a considerar muchas empresas de importación y exportación propiedad de extranjeros: alemanes, escandinavos, franceses y belgas, que son especialmente activos en estos negocios. BEA, OV61/2, fol. 10/2 y fol. 11. 
Esta crítica se entiende mucho mejor a la luz del informe que sobre «Presupuesto Nacional y Deuda Pública» encontramos en los archivos del Foreign Office, cuyo redactor asevera: «El presupuesto español padece de una enfermedad crónica que se llama insinceridad...». Dentro del referido informe se da cuenta de que «no hay ninguna estadística española recopilada con sinceridad» y para evidenciarlo se coteja el importe de la deuda pública consolidada el 1 de abril de 1936, según datos publicados por la Dirección General de la Deuda y Clases Pasivas, con otras cifras que corresponden a la deuda flotante emitida en obligaciones del Tesoro en 1934, 1935 y 1936. El resultado final es una infravaloración de la deuda pública en unos 7.000 millones, cifra que se debería sumar a la declarada por la referida Dirección General. ${ }^{43}$

Como afirma Fernando Celestino Rey $(2001,4)$, «gran parte de la estadística oficial durante la Guerra Civil está aún por escribir, especialmente lo referente a lo acaecido en la zona republicana». A pesar de todo, las cifras de inversiones extranjeras ofrecidas por el informe Moody en el Draft Memorandum... son las mejores cifras disponibles porque, por ahora, no hay otra estimación de coetáneos que podamos utilizar. El «draft memorandum regarding the nature and extend of foreign interest in Spanish finance, commerce an industry» ofrece unas cifras que se entiende intentan valorar la inversión extranjera directa, así como la realizada en cartera. Los documentos contenidos como una unidad dentro del legajo que relaciona las inversiones «non-british» permiten afirmar que la valoración cuantitativa incluye ambos tipos de inversiones. ${ }^{44}$

Otro tema es el de la bondad de la estimación que los funcionarios del Banco de Inglaterra ofrecen en las cifras que aparecen en el informe (ver el borrador del memorando, BEA, OV1/2, fol. 10/2). Se ha contrastado la cifra de la inversión directa norteamericana en España del Moody's, y se advierte que infravalora en un 15,04 por ciento la ofrecida por el Censo del US Department of Commerce/ Bureau of Foreing and Domestic Commerce $(1938,9)$. Se ha corregido la cifra para 1936 y después se ha actualizado su valor en dólares de 1940, utilizando

43. Ver FO, 371, 22670, diversos documentos dirigidos al Foreign Office desde la «British Embassy; Caldetas, Barcelona».

44. El primer párrafo del folio 8c permite sacar esta conclusión: «... it may, broadly speaking, be said that all major enterprises in Spain whether banking mining or manufacturing are either under British or other foreign control, or have a substantial British or foreign interest $»$. El informe, a pesar de resultar impreciso, valora la existencia de un importante interés británico o extranjero en empresas radicadas en España, además del interés extranjero que detenta el control (IDE), es decir también la participación portfolio extranjera. En caso de opinión en contrario se trataría sólo de las inversiones directas, lo cual supondría una infravaloración algo mayor que la supuesta por los empleados del Banco de Inglaterra. Ver BEA, OV61/2, vols. 3, 4 y 5 (2169/4). 
el deflactor de GDP. El caso de los Estados Unidos es el único del cuadro para el que se aporta sólo la inversión directa en España, tanto en 1936 como en 1939, y este último dato Cleona Lewis especifica que refiere la inversión directa USA de 1940.

En la carta de 28/10/1936 que Morton dirige a Bridges (BEA, OV1/2, fol. $8 / b)$ ya se percibe claramente que el Memorando es un «informe de mínimos» y parece positivo, en función de la mejor estimación posible de esas inversiones extranjeras, que los funcionarios del Overseas sean conscientes de este extremo. A lo largo del informe se observa su intención y ansias de reparar el menoscabo de las cifras y menciones a empresas que deben considerarse. En la carta mencionada D. Morton tiene la esperanza de que el Tesoro (la Hacienda Pública) pueda contar con información que en el mejor de los casos permita reforzar el Memorando y que en el peor constituya una comprobación para asegurar que no hay intereses de importancia pasados por alto.

Por consiguiente, al igual que reparamos la infravaloración de la IDE norteamericana para 1936, no le aplicaremos ningún coeficiente corrector a las cifras del resto de inversores extranjeros para ese año. No se podría establecer qué ponderación sería la más adecuada y repercutirle la hallada para la inversión directa USA no parece atinado. La decisión que tomamos en aras de la mayor homogeneidad posible, al realizar la comparación ofrecida en el cuadro 4, es la de contar con la coherencia de utilizar un sesgo parecido y ése es el sesgo de las cifras provenientes de diferentes norteamericanas (ver fuentes y notas del cuadro 5). Las estimaciones del Moody's Investor Service son utilizadas tanto por los empleados del Banco de Inglaterra (1936) como por Cleona Lewis para sus Balances Sheets (1939/1940). ${ }^{45}$

Con las miras puestas en esa comprobación que asegure no pasar por alto intereses extranjeros relevantes, y procurando tomar la información cuantitativa de fuentes norteamericanas, conseguimos la imagen del cuadro 4 que nos marca la tendencia de una lógica desinversión -en 1939 un 17,88\% menos que la inversión estimada para 1936- durante los años de la Guerra Civil. Lo esperado del descenso en el montante de inversión extranjera -directa y portfolio- existente

45. Cuando Cleona Lewis, gran experta en la contabilidad nacional de los Estados Unidos, explica las fuentes utilizadas en su estudio indica que: 1) aunque haya manejado diversas fuentes, cuando existe acuerdo general sobre ellas, sólo cita la original de los datos en cuestión; 2) prefiere las cifras compiladas por las agencias gubernamentales de los países y también algunos estudios semioficiales, muchos se publican anualmente por la League of Nations en sus Balance of Payments series; 3) también utiliza materiales no publicados e informes no oficiales disponibles gracias al Department of Commerce; provenientes de la sección de extranjero del Moody's Governments and Municipals; de la sección del Overseas Trade (United Kingdom)... Ver Lewis (1948, 286-87). 
en 1939 se basa en la inseguridad provocada por el conflicto y la falta de expectativas de beneficios para los inversores durante el mismo, además de contar con la posible destrucción de activos o deterioro importante de ellos que influyan en el cálculo de la estimación de su valor. Por supuesto las dificultades en la repatriación de beneficios constatadas por el Cónsul británico en Barcelona para 1935 se deben tener muy en cuenta.

En 1936 contamos al menos con tres valores diferentes para aplicar a la cotización de la peseta en dólares norteamericanos. ${ }^{46}$

Cuadro 4. Pesetas por dólar USA, en 1936

\begin{tabular}{|c|c|c|}
\hline Federal Reserve Bulletin (1940) & Viñs $(1979,192)$ & Martín Aceña y Pons $(2005,705)$ \\
\hline 12,99 & 10,70 & 7,46 \\
\hline
\end{tabular}

Nota: El dato del FRB está tomado del US Department of Commerce (1940, 42). El dato de Martín Aceña y Pons $(2005,706)$ está tomado de Dixon (1994).

Para seguir fieles a la pretendida coherencia de tomar idéntico sesgo y que lo marquen las fuentes americanas, aceptaremos el valor de 12,99 pesetas por dólar USA a la hora de pasar las pesetas de 1936 a dólares de $1936 .{ }^{47}$ Esta opción queda reforzada por el valor que ofrece la misma fuente, el Federal Reserve Bulletin, para el siguiente año de 1937: un dólar alcanza la cotización de 16,39 pesetas ${ }^{48}$. Para actualizar el valor de los dólares de 1936 utilizamos el deflactor del GDP y así lo tenemos expresado en dólares de 1939. Con la observación de las precauciones comentadas al elegir los valores de las cotizaciones de la peseta y demás

46. El dato aportado por ViÑAs et al. $(1979,192)$ para las «divisas libres importadas voluntaria y definitivamente» da la cifra de 10,70 para la fecha de 31-12-1936. El dato de Viñas es el de pesetas por moneda extranjera publicado por el Comité de Moneda Extranjera (19361939). Pero en el report del US Department of Commerce (1941, 110) se señala que el valor de la peseta arbitrariamente fijado al empezar la guerra por el Gobierno Nacionalista se ha mantenido en gran parte durante todo 1939. Se cifraba el cambio oficial para dólares procedentes de exportaciones en 10,95 pesetas y para ventas libres en 12,56 pesetas por dólar (25-abril-1940). El valor de las divisas procedentes de exportaciones resulta inferior a las cotizaciones de la peseta hasta ahora referidas y por consiguiente se desprecia dicha cotización, pues parece poco cercana a la realidad. Dixon $(1985,219)$ por ejemplo, para 1938, tachaba las cifras oficiales de infravalorar las reales.

47. La información contenida en el Draft Memorandum para las principales inversiones extranjeras está valorada en pesetas, con la excepción de la inversión directa norteamericana que lo está en dólares. Ver BEA, OV61/2, fol. 10/2.

48. Esta referencia la da Cleona Lewis (1948) en su apéndice A, p. 289. 
reticencias acerca de la infravaloración de las cifras de inversiones extranjeras del cuadro 5, parece correcto afirmar que estamos comparando magnitudes bastante homogéneas. ${ }^{49}$

Cuadro 5. Inversiones extranjeras en España, 1936 y 1939 (en dólares de 1939)

\begin{tabular}{|c|c|c|c|c|}
\cline { 2 - 5 } \multicolumn{1}{c|}{} & 1936 & 1939 & $\begin{array}{c}\text { 1939-1936 } \\
\text { DIFERENCIA (EN \%) }\end{array}$ & Ranking en 1939 \\
\hline Nacionalidad & A & B & {$[(\mathrm{B}-\mathrm{A}) / \mathrm{A}] \mathrm{x} 100$} & 1 \\
\hline Francesa & 170,90 & 135 & $-21,01$ & 3 \\
\hline Británica & 51,14 & 42,1 & $-17,67$ & 2 \\
\hline USA * & 81,34 & 73,4 & $-9,76$ & 4 \\
\hline Belga & 33,87 & 26,8 & $-20,88$ & 6 \\
\hline Alemana & 9,62 & 7,6 & $-21,02$ & 5 \\
\hline Italiana & 0,54 & 0,4 & $-25,77$ & $-17,88$ \\
\hline Total & 347,41 & 285,3 & & \\
\hline
\end{tabular}

* Los 80,53 millones de dólares son inversión directa US en España. Ver US Department of Commerce $(1938,9)$. El año para USA es 1940: se ha actualizado (deflactor del GDP) el valor de los dólares de 1936 a su valor en 1940 (\$1,01).

Fuente: Samuel H. Williamson, «Five Ways to Compute the Relative Value of a U.S. Dollar Amount, 1790 - 2006», MeasuringWorth.Com, 2007. Tascón/Carreras, 2000. Cleona Lewis, 1948, p. 315.

En 19361 dólar USA = 12,99 pesetas. Federal Reserve Bulletin, cit. en American Direct Investments abroad $(1940,42)$. In 1939, $\$ 1.00$ from 1936 is worth: \$1.00 using the GDP deflactor.

Para el dato de USA (Census) el valor de la inversión directa US $=80,53$ millones de dólares. En 1940 el dato USA (Census) también es sólo inversión directa.

Por dicho motivo la diferencias entre el contingente de inversiones extranjeras que había en España entre los años extremos de la guerra, 1936-1939 -para USA sólo las inversiones directas, 1936-1940- aparecen salvo en dos casos sobrepasando la reducción del 20 por ciento. Las excepciones son la británica y la más paradigmática de todas la estadounidense, sólo un 9,76 por ciento de reducción respecto al valor de lo invertido para detentar el control en las empresas radicadas en España.

49. Respecto a esas infravaloraciones, los empleados del Banco de Inglaterra ya lo habían indicado para el caso de los aludidos intereses belgas y otros en PYME's, cit. en BEA, OV61/2, fol. 10/2. y fol. 11. 
La reducción del flujo inversor extranjero acaecida entre los años de la guerra, 1936-1939, tuvo unos prolegómenos anunciados por la evolución del comercio exterior desde el comienzo de la Segunda República, además de corresponder de pleno el período a la Guerra Civil. La tendencia de exportaciones e importaciones estuvo marcada por el signo de un progresivo declive desde 1931 a 1939, con algunos pequeños repuntes intercalados. ${ }^{50}$ Lo declarado por el Cónsul General del Reino Unido en Barcelona corrobora con su testimonio que existían ya dificultades soportadas en los últimos años -se refiere a los años más cercanos a 1936- por el capital extranjero:

Of recent years foreign capital in Spain has been subjected to many difficulties.

In the early part of 1935 His Majesty's Consul General at Barcelona reported that for some considerable time there had been no investments of any importance of foreign capital into Cataluña. He added that it was unlikely that there would be any in the future until the situation became cleared, and foreign capitalists felt more confidence in the Government. The general attitude towards the Spanish authorities of foreign companies undertaking, for example, construction work, was then hostile. Repatriation of foreign capital in Spain was difficult. ${ }^{51}$

La secuencia de un comercio exterior en retroceso que induce una reducción de la inversión extranjera, unida a testimonios como el del Cónsul inglés, parecen contradecir lo afirmado en su día por Tamames $(1968,349)$ : «...hasta 1936 la inversión extranjera no encontró ninguna clase de trabas en España. El capitalista extranjero gozaba de completa libertad para invertir, para transferir sus beneficios y para realizar desinversiones».

Cabe intuir la certeza de un declive en lo invertido globalmente desde el extranjero, porque, como ya sabemos, los propios empleados del Bank of England reconocen la seria infravaloración de la información para 1936.52 Además, hemos ponderado las pesetas de 1936 utilizando un tipo de cambio que a buen seguro está por debajo del de mercado (es decir del no oficial) para la mayoría del capital extranjero en España. Un sencillo cálculo como expresar las unidades monetarias, por ejemplo, en pesetas de 1913, permite observar un decrecimiento de la inversión extranjera total de un 36,91 por ciento durante el período, 1936-

50. Cuadro A7.4, en Prados $(2003,483)$. El cuadro muestra la tendencia a la baja de ese comercio exterior.

51. Bank of England Archive, OV61/2, vols. 3, 4 y 5, (2169/4), 8c.

52. Sobre esa subestimación, sobre todo para el caso de las empresas suizas, véase TAscón y Carreras (2001, 477-479). Hemos realizado un ejercicio para reconstruir el mismo cuadro 4 contando con actualizar los valores de esas inversiones extranjeras en pesetas de 1939 y valorando la inversión directa norteamericana según la cotización de 12,56 pesetas por dólar, para el 31/12/39 (VIÑAS, 1979, 192). Entonces las inversiones de capital procedente de los Estados Unidos se habrían incrementado en un 0,24 por ciento y esto sí resulta congruente con la constitución de las filiales USA de 1936 y 1937. 
1938, que se convierte en un 40,58 por ciento si medimos el decremento en la inversión privada extranjera por habitante (ver cuadro 5). El triunfo del bando nacional parecía ya bastante claro para ese año 1938 y no resulta difícil obtener porcentajes más abultados de la reducción en el contingente de inversiones extranjeras para 1939 si manejamos las cifras del siguiente modo. Sencillamente con tomar del cuadro 5 los valores para 1936 aplicándoles el tipo de cambio de 1 dólar USA = 7,46 pesetas para medir las diferencias como en ese mismo cuadro 5, en dólares de 1939, el porcentaje medio de la reducción sería del 47,62 por ciento ${ }^{53}$. Para marcar la tendencia -como es nuestro interés declarado más arriba- son válidos perfectamente los datos que parecen tener mayor sentido, los del cuadro 5. Aunque por otros procedimientos que ahora no podemos aplicar, por ausencia de información, se podría llegar a cotas de desinversión como las que aparecen en la nota 52. La reducción en las inversiones extranjeras queda contrastada favorablemente, como cabía suponer a la luz de la información del declive del comercio exterior desde los años de la Segunda República.

53. Inversiones extranjeras en España, 1936-1939 (en dólares de 1939)

\begin{tabular}{|l|c|c|c|}
\cline { 2 - 4 } \multicolumn{1}{c|}{} & 1936 & 1939 & Diferencia en porcentaje \\
\hline Nacionalidad & $\mathrm{a}$ & $\mathrm{b}$ & {$[(\mathrm{b}-\mathrm{a}) / \mathrm{a}] \%$} \\
\hline Francesa & 297,59 & 135,00 & $-54,64$ \\
\hline Británica & 89,05 & 42,10 & $-52,72$ \\
\hline USA $*$ & 81,34 & 73,40 & $-9,76$ \\
\hline Belga & 58,98 & 26,80 & $-54,56$ \\
\hline Alemana & 16,76 & 7,60 & $-54,64$ \\
\hline Italiana & 0,94 & 0,40 & $-57,37$ \\
\hline Total & 544,64 & 285,30 & $-47,62$ \\
\hline
\end{tabular}

* El año es 1940: para USA se ha actualizado -deflactor del GDP- los dólares de 1936 a su valor en 1940 (\$1,01).

Fuentes: Samuel H. Williamson, «Five Ways to Compute the Relative Value of a U.S. Dollar Amount, 1790 - 2006», MeasuringWorth.Com, 2007.

Tascón y Carreras, 2000. Cleona Lewis, 1948, p. 315.

En 19361 dólar USA = 7,46 pesetas. Dixon (1994), cit. en Martín Aceña y Pons (2005, 705-706).

In 1939, $\$ 1.00$ from 1936 is worth: $\$ 1.00$ using the GDP deflactor.

Para el dato de USA (Census) el valor de la inversión directa US $=80,53$ millones de dólares.

En 1940 el dato USA (Census) también es sólo inversión directa. 
Cuadro 6. Capital extranjero invertido en España, 1936-1938

(Capital público \& Deuda Externa excluidos)

\begin{tabular}{|l|c|c|c|}
\hline & $\begin{array}{c}\text { MilLONES DE PESETAS COR- } \\
\text { RIENTES }\end{array}$ & $\begin{array}{c}\text { Millones DE PESETAS } \\
\text { (PESETAS DE 1913) }\end{array}$ & $\begin{array}{c}\text { InVERSIÓN PRIVADA EXTRANJERA POR } \\
\text { HABITANTE (MILLONES DE PESETAS } \\
\text { DE 1913) }\end{array}$ \\
\hline $1936^{*}$ & $4.137,29$ & $2.425,12$ & 101,86 \\
\hline 1938 & $3.243,86$ & $1.530,12$ & 60,53 \\
\hline
\end{tabular}

* Sólo empresas de los 7 países principales inversores: Francia, Reino Unido, USA, Bélgica, Suiza, Alemania e Italia.

Cifras de población total (a 1 de julio) tomadas de Roser Nicolau (1989, 70-71).

Fuente: elaboración propia y Tascón (2005, mímeo).

La notable excepción de la inversión exterior norteamericana y su singularidad cabe atribuirla dentro del camino de los Estados Unidos para asumir el liderazgo económico mundial. Aunque es bien conocido el retraimiento de sus inversiones directas durante la década de los treinta. Tampoco se debe desdeñar lo que los americanos tienen acendrado como una relación bastante obvia, la que se da entre sus «overseas investments to US imports» (Carroll, 1956, 54), la cual para nada es un patrimonio exclusivo de esa nación. Charles R. Carroll señala cómo el papel desempeñado por empresas comerciales estadounidenses en el extranjero es decisivo y vital para satisfacer las necesidades actuales de los norteamericanos. ${ }^{54}$ De hecho tenemos constancia a través de un informe confidencial del Overseas and Trade Department del Banco de Inglaterra de la evolución de la balanza comercial española con diferentes países y la evolución del valor de las exportaciones hacia EE. UU. se afirma claramente desde 1935 a 1937, pues el saldo negativo de la balanza se reduce. Se atribuye el saldo desfavorable de las importaciones por EE. UU. a las importaciones de bienes de lujo y de cualquier forma se apunta la minoración del comercio internacional español para esos años. Los Estados Unidos y el Reino Unido, para 1937, están realizando operaciones comerciales con ambos bandos, rebelde y republicano, al tiempo que Alemania se afianza como principal exportador a la España de Franco. Ya le atribuyen a Franco una balanza comercial con sólo un ligero saldo negativo y parece fácil colegir que los Estados Unidos son sensibles a este tipo de informa-

54. Ver Carroll $(1956,55)$. Por supuesto, sigue siendo consulta obligada lo expuesto por Dunning (1976) y más reciente por Dunnig y NARula (1996). 
ción. Por ello se entiende mejor el asentamiento y perseverancia de sus intereses empresariales en suelo español aguantando el conflicto bélico. ${ }^{55}$

Posiblemente, la ligera reducción del ahorro yanqui en España puede responder a una mera pauta de inversión obligada por el marco legal del momento. Ya en 1935 el Cónsul general de Barcelona hacía constar que «Repatriation of foreign capital in Spain was dificult» (citado más arriba), y además mencionaba compañías extranjeras que al experimentar dificultades para obtener el permiso para repatriar beneficios invertían sus ganancias en España. ${ }^{56}$ El Decreto de 5 de julio de 1937 prohibió disponer libremente de los saldos en pesetas existentes en cuentas a favor de titulares residentes en el extranjero. ${ }^{57}$

El riesgo-país soportado también depende de la valoración particular y la opinión de los extranjeros con intereses económicos en España que, ya en 1938, ni era homogénea ni absolutamente contraria al desempeño empresarial dentro de las fronteras españolas, bien nacionales o republicanas. ${ }^{58} \mathrm{La}$ información del siguiente gráfico para la inversión directa norteamericana permite percibir que no se trató, únicamente, en aquel caso de una reinversión de beneficios. La dirección en la que apunta el establecimiento de nuevas filiales durante el conflicto bélico, aunque no podamos estar del todo seguros, es la de una apuesta por la rentabilidad de las fortalezas del modelo inversor que ofrecía España al capital americano. Es decir que algunos inversores confiaron a pesar de la guerra, o mejor dicho perseveraron en función de las garantías que les merecía su percepción en las relaciones con los nacionales. Tal vez gracias al rumbo que tomaba la contienda, decidieron seguir arriesgando en función de las expectativas que para 1938 daban ya la victoria al bando rebelde. ${ }^{59}$ La tendencia por sectores enseña la

55. Ver BEA, OV61/3, Confidencial Spanish Foreign Trade.

56. BEA, OV61/2, p. 8c. Cit. en TASCÓN $(2003,285)$. Dado el peso relativo de la región catalana dentro de la economía española, el aserto del cónsul contradice la idea de Tamames, quien consideraba que hasta 1936 la inversión extranjera «había gozado prácticamente de plena libertad». Cit. en Aznar Sánchez $(1976,25)$.

57. Se advertía, en el Decreto de 1937, que para movilizar dichos fondos habría de solicitarse con carácter previo y en cada caso autorización del Comité de Moneda Extranjera expresando en la solicitud el destino que se dará a los recursos. Ver Aznar Sánchez, ibidem.

58. Informes del BEA o del FO, del Banco de Bilbao para operar pagando un tanto por aceptar la colectivización.

59. En el Confidential Spanish Foreign Trade (BEA, OV61/3), redactado en agosto de 1938, se daba la victoria económica a la balanza comercial de los nacionales, con el matiz de mostrar sólo un pequeño déficit para 1937. Allí se afirma que la España republicana parece importar más que el territorio de Franco, lo cual ponía de manifiesto las dificultades en alimentar la población en la zona de la República. Se afirma textualmente que la España republicana se encontraba peor que antes con un déficit en contra de 4,1 millones de libras esterlinas, para 1937; incluso contando con que el déficit de la balanza por cuenta corriente está ajustado a 2,1 millones de libras esterlinas con Rusia como una deuda que 
predilección de la inversión directa norteamericana por el petróleo, las manufacturas, transportes, comunicaciones, obras públicas y comercio. ${ }^{60}$

Filiales norteamericanas establecidas en España, 1868-1950

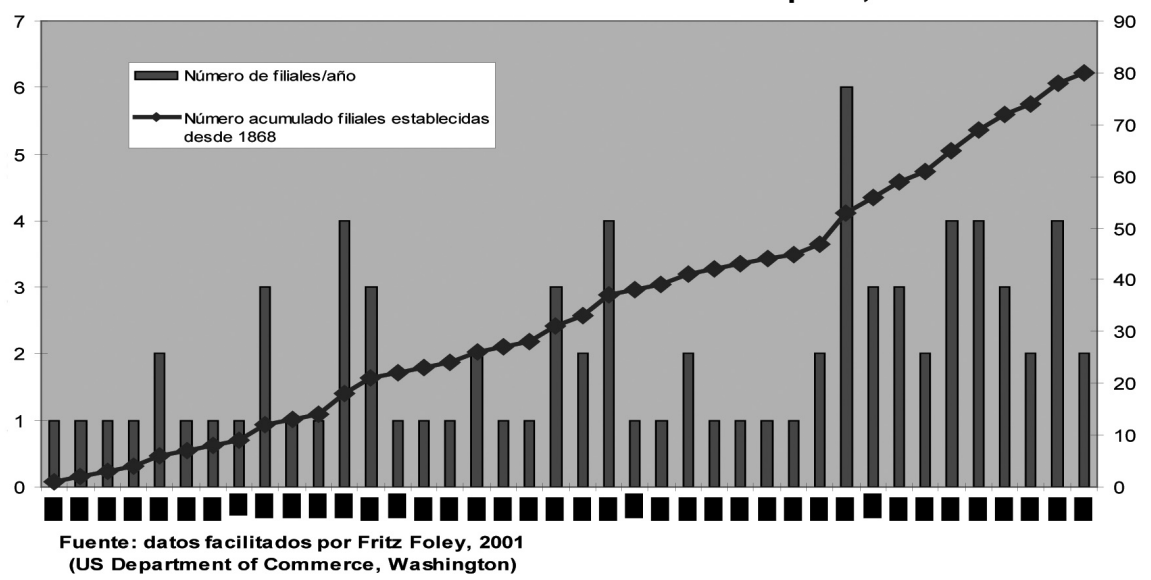

Desde 1931 a 1939 las filiales de matriz norteamericana establecidas arrojan una media de 1,25 filiales por año ${ }^{61}$. Esto concuerda con la posición del capital norteamericano invertido en España, que arroja un decremento del 9,76 por ciento, para el intervalo de 1936 a 1939. Parece bastante significativo tomar la

debe ser saldada a través del clearing (Overseas and Foreign Department, 22 de agosto de 1938).

60. El siguiente cuadro nos revela las preferencias mencionadas, en consonancia con el abastecimiento del mercado interior norteamericano como algunos tratadistas suelen exponer, por ejemplo véase Carroll (1954).

Inversiones directas norteamericanas en España, 1929-1943 (millones de dólares)

\begin{tabular}{|l|c|c|c|c|c|c|c|c|}
\hline & Agricultura & Petróleo & Manufacturas & $\begin{array}{c}\text { Transp. Com. y } \\
\text { obras públicas }\end{array}$ & Comercio & $\begin{array}{c}\text { Finanzas } \\
\text { y seguros }\end{array}$ & Varios* & TOTAL \\
\hline 1929 & & 8.5 & 12.4 & & 4.0 & & 47.3 & 72.2 \\
\hline 1936 & & 1.4 & 16.3 & & 1.4 & & 61.4 & 80.5 \\
\hline 1940 & & 2.0 & 11.0 & 52.3 & 3.9 & & 4.3 & 73.4 \\
\hline 1943 & 0.4 & 1.7 & 17.5 & 89.7 & 5.8 & 1.0 & 8.2 & 124.3 \\
\hline
\end{tabular}

Tascón (2005, mímeo).

61. Los datos que compila y me suministra Fritz Foley durante su estancia en el US Deparment of Commerce (Office of Business Economics) Washington, contienen una ausencia de información para 1938, que se puede interpretar como una nula inversión directa para constituir una filial de una multinacional americana en España. La media aritmética simple del período 1931-1935 sería entonces 1,11 filiales nuevas por año. 
decisión de constituir una filial por año durante la Guerra Civil, pues cuando menos parece que habrían tenido que reducir la actividad a mínimos de explotación. La media de la etapa subsiguiente $1940-50$ es de 3,3 filiales por año ${ }^{62}$. Parece lógico pensar en cierta desinversión según sectores de actividad afectados por la guerra y según zonas, al tiempo que son compensadas por otras inversiones, en el lado nacional que es donde parece contar la actividad económica con menores riesgos. ${ }^{63}$ La progresión con un salto entre décadas de una media de 1,11 filiales por año instaladas en España durante los años treinta, a una media de 3 en los cuarenta, constituye un pequeño pero meridiano exponente del poderío económico de la nación americana de entonces: un incremento del 170 por ciento en la creación de filiales bajo el control de capital americano, sin contar con las empresas participadas donde no detentaban el control societario. ${ }^{64}$

El marco global de los flujos de capital para la época de la Segunda República hace bueno el proverbio que pronostica cómo lo que puede ser perjudicial para una mayoría no implica la mejoría particular de algún agente. ${ }^{65}$ Los datos globales (tomando una amplia muestra de países) de Obstfeld y Taylor (1997) sobre el alcance de esos movimientos de capital arrojan el mínimo saldo del período 1870-1996: un 1,2 por ciento del Producto Interior Bruto para la etapa de 1932 a 1939. Sin embargo, la inclinación del ahorro americano por invertir en España se manifestaría de manera significativa durante aquellos años, como atestigua el crecimiento de 1929 a 1936 ya apuntado más arriba. También se percibe claramente con el peso de la inversión directa estadounidense de 1929

62. Si la ausencia de datos en el caso de 1946 se interpreta como la inexistencia de creación de filial alguna ese año, la media resultante sería de 3 filiales por año, en lugar de las 3,3 mencionadas.

63. Según las cifras del cuadro de la nota 17: Inversiones directas norteamericanas en España, 1929-1943, se observa ciertos cambios que pueden coincidir con ese movimiento compensador de los inversionistas americanos.

64. Se debe considerar las apreciaciones de Martínez Ruiz (2005, 68), que, tomando la información de Viñas y García Pérez, destaca un flujo de inversión alemana (1936-1939) debido al capital desembolsado en Sofindus de 15 millones de dólares. Esta variable flujo sería el aumento de la inversión alemana para la época de la Guerra Civil. Tal vez resulte concordante con un crecimiento del flujo inversor entre 1938 y 1939, pero resulta difícil precisarlo por ahora debido a las diversas cifras de los activos alemanes para 1939, según diferentes autores. La variable stock de 1938 proporcionada por Cleona Lewis son 7,6 millones de dólares, si tomamos la cifra de 29 millones para 1939, proporcionada por Martínez Ruiz, el flujo inversor alemán habría aumentado en 21,4 millones de dólares, entre 1938 y 1939 , pero es una mera conjetura.

65. Mejoría entre comillas, pues lógicamente en un contexto como el propiciado por el escenario de la Guerra Civil española, la mejoría particular es siempre relativa. Eso si la perseverancia asegura y reafirma la red de intereses y de empresas estadounidenses en España. 
a 1943, según los datos censales disponibles, en comparación con otros países, incluidos los neutrales durante la Segunda Guerra Mundial.

\section{Cuadro 6. Peso relativo de las inversiones directas norteamericanas} en algunos países de Europa, 1929-1943

\begin{tabular}{|l|c|c|c|}
\cline { 2 - 4 } \multicolumn{1}{c|}{} & 1929 & 1936 & 1943 \\
\hline Italy & 8,35 & 5,56 & 4,14 \\
\hline Greece & 0,37 & 0,71 & 0,49 \\
\hline Portugal & 0,89 & 0,48 & 0,68 \\
\hline Spain & 5,32 & 6,35 & 6,05 \\
\hline Sweden & 1,40 & 1,99 & 1,61 \\
\hline Switzerland & 1,26 & 0,71 & 2,15 \\
\hline France & 10,72 & 11,60 & 8,14 \\
\hline Germany & 16,04 & 18,11 & 25,01 \\
\hline United Kingdom & 35,85 & 37,65 & 25,30 \\
\hline Turkey & 0,67 & 1,11 & 1,27 \\
\hline
\end{tabular}

Fuente: US Census.

Por lo tanto, la inversión exterior en España tiende a reducirse, con la salvedad de la procedente del ahorro norteamericano que evoluciona, en la agonía comercial de la Segunda República, como la excepción a la regla. Como excepción la confirma, pues basta observar los datos del comercio exterior español con Estados Unidos para comprobar su disminución drástica. Sin embargo, el capital americano invertido disminuye hasta 1940, según los datos disponibles, sin un excesivo catastrofismo. ${ }^{66}$ Tal vez algunos indicios económicos positivos en la zona republicana ayudaban y reanimaban -en lo posible- las inversiones, como el Banco Comercial y de Crédito inaugurado para proveer créditos a la industria, en 1938 (Juliá, 1938, 221). También retrocede el capital alemán dentro de la tónica de reducción del flujo inversor extranjero apuntada para 1936-1939 (ver cuadro 5) y es un resultado conforme con el descenso en el comercio exterior con Alemania -1935-1938- calculado para ambas zonas, republicana y nacional, por Viñas (1979, 242 y ss.).

Tal vez se pueda sostener que existió un notable incremento de la actividad inversora alemana dentro del marco de la inexistencia de desinversión alguna de

66. Otro testimonio que corrobora cierta bonanza económica es un artículo aparecido en la Vanguardia de Barcelona, el 10 de mayo de 1938 titulado: «Los intereses de las empresas extranjeras en España están a salvo». Ver Public Record Office, Foreign Office, 371, 22685. Spanish volumen of Survey of International Affairs to Mr. Roberts, dated $14^{\text {th }}$ May 1938. 
importancia, para el período de la Guerra Civil (Martínez Ruiz, 2005, 67). Este argumento aplicado a las inversiones a largo plazo de la época implicaría una pequeña reflexión sobre la siguiente convención: la diferencia entre dos variables stock es un flujo. De acuerdo con esta definición cabe interpretar con cierta cautela el incremento de la inversión directa alemana. Casi con seguridad los 24 millones de marcos del crédito en divisas, facilitado por la ROWAK al holding Sofindus para participar en las empresas alemanas en España señaladas por Viñas (1979, 344-5), se realiza en 1939 y no a lo largo de los años de guerra precedentes como se podría pensar ${ }^{67}$. Es decir que el flujo de la desinversión de capital alemán, según las cifras aportadas aquí para cuantificar dicho capital entre 1936 y 1939, no se contradice con la inyección del crédito de la ROWAK para 1939, año en el que la valoración de la victoria de los nacionales, el riesgo-país aparentemente más reducido y las necesidades de importación alemanas alentaron la decisión de otorgar dicho crédito. El momento y las condiciones financieras de ese crédito en divisas, así como los canales utilizados por la ROWAK pueden justificar su ausencia en el montante global que incluye las inversiones a largo plazo alemanas controladas por Cleona Lewis ${ }^{68}$. De modo que sí hubo un conflicto bélico que animó la desinversión de capitales extranjeros en esos años, independientemente del interés nazi en incrementar sus inversiones directas a través de Sofindus en 1939.

La relación histórica atestigua que el comercio físico entre naciones trajo la inversión extranjera a ellas y asimismo resulta relevante la comprobación de una disminución del comercio exterior y su consiguiente afectación del desarrollo normal y del funcionamiento de muchos tipos de inversión exterior que lógicamente se reducirán a su vez (Carroll, 1954, 51)69. Por esta razón esencial, cuando exponemos los datos inéditos del informe del señor Juliá sobre el comer-

67. Dicha interpretación, después del paper de 2005, aparece en MarTínez Ruiz (2006, 313 y 316), que además la refuerza con la mención a las inversiones de la HISMA durante la Guerra Civil, desde 1937. No aporta ninguna cuantificación para avalar la tendencia apuntada.

68. Para que tal crédito se materialice en las inversiones correspondientes y pudiera contabilizarse convenientemente, es posible que al menos se tratase del ejercicio económico siguiente, del año 1940. Pero respecto a las cifras del cuadro 5 debemos tener en cuenta que cuando Cleona Lewis $(1948,315)$ ofrece el montante en dólares del total de inversiones alemanas en España, hay que pensar que ella se justifica sobre el contenido cuantitativo del apéndice A -donde está incluida esa cifra- del siguiente modo: «The figures cover only long-term items, since short-term data are not available for most countries», LEWIS $(1948,285)$.

69. El tipo de relación entre el comercio y la inversión exteriores del caso español, y más exactamente para la inversión directa extranjera, de los años sesenta en adelante, se puede consultar en los trabajos de Óscar Bajo et al., o en el de Caballero Sanz, Ortí Lahoz y Orts Ríos (1989). 
cio exterior de la República, el corolario de esa evolución que se adentra en la Guerra Civil es la inevitable minoración de una inversión exterior que no había contado con demasiada ayuda, y sí con un comercio exangüe según todos los datos disponibles desde 1931 hasta 1939.

Cabe pensar después de lo expuesto aquí que queda suficientemente demostrada la ya reiterada relación entre el comercio y la inversión exteriores de un país: España durante la Guerra Civil (1936-1939), en nuestro caso. Destaca el particular comportamiento del ahorro norteamericano dentro de la pauta de una significativa reducción, en general, de la inversión extranjera, alentada por el fortísimo declive del comercio exterior español.

\section{Reflexiones finales}

Las siguientes observaciones finales atienden primero a una recapitulación sobre el panorama del comercio exterior, para después pasar a la evolución de la inversión extranjera, con especial atención al caso de la norteamericana. Para concluir apuntamos cómo la caída del comercio exterior arrastra, o bien trae consigo, la caída de la inversión extranjera. Aquí indicaremos también la influencia que tuvo la reacción proteccionista a la Gran Depresión y lógicamente, al final de la Segunda República española, las condiciones impuestas por la Guerra Civil.

El comercio de importación y exportación en la España republicana era un ejemplo totalitario de economía dirigida e intervenida íntegramente por el Estado. «Para ser comerciante en España se necesita tanto heroísmo como para ir al frente de batalla...». Pero además, como es fácil suponer, «en los tiempos de la guerra todos los servicios estaban desorganizados, por deserciones de unos, por traslados de una a otra ciudad, por la intervención violenta en los despachos de mercancías que estaban en muelles y almacenes oficiales por comités revolucionarios insolventes, que no sólo se negaron a pagar derechos de importación sino a facilitar datos de las mercancías incautadas en compañía de la documentación». ${ }^{70}$ Las estadísticas oficiales estaban sujetas a márgenes de error que la misma evolución de la guerra hace entender. Pero a simple vista, a pesar de ocultaciones e inexactitudes, resulta evidente el colapso de las importaciones, aunque como afirma Julià «las de productos alimenticios resultan casi tan altas para el territorio republicano

70. Hay que añadir sobre la fiabilidad de los datos que resultaba difícil ya admitirla en tiempos normales, debido al sistema de ocultaciones y falsas valoraciones que dominan desde hace muchos años la política aduanera española. Por si esto fuera poco, el Gobierno no hace figurar en las estadísticas - para no facilitar pruebas al Comité de la No Intervención- el material de guerra que importa, como tampoco hace constar el valor de las joyas y del oro exportado por las Subsecretarías de guerra, municiones, aire, marina, y abastecimiento. Ver Julià, 1938, 38 bis y 35 (346). 
como en tiempos normales para toda España. Lo que continúa importándose es absolutamente indispensable para la vida nacional». La explicación puede estar en que la población contabilizada en territorio republicano era tan sólo unos dos millones de personas menos que la del territorio nacional ${ }^{71}$.

El comerciante o industrial residente en España que deseaba importar algún tipo de mercancía (producto natural, artículo fabricado) debía solicitar el oportuno permiso a la Dirección General de Comercio y ésta era muy exigente con todos los detalles que mandaba cumplimentar al importador, los cuales venían especificados en la Gaceta de la República del 23 de noviembre de $1937^{72}$. Si eran mercancías para las industrias, la de Comercio pedía informe a la Dirección General de Industria, si era comercial el informe debía enviarlo la de Economía, si se trataba de alimentos la de Agricultura, si se trataba de operaciones bancarias la del Tesoro, Banca y Seguros. Una vez que todos los asesoramientos eran favorables, se obtenía el permiso necesario y entonces el importador tenía que depositar en el Banco Exterior de España la cantidad o una garantía de lo que alcanzaba la mercancía solicitada; sólo a partir de entonces podría recibir los géneros. Para los exportadores no era menos trabajoso el proceso que también pasaba a través del Banco Exterior, el único que podía hacerse cargo de los pagos de mercancías importadas y del cobro de las exportadas. Quien ordena y manda y quien ejecuta al mismo tiempo, pues al Centro de Contratación de Moneda se le han constreñido sus facultades, es la Dirección General del Tesoro, o mejor dicho -afirma Julià- el propio ministro de Hacienda, Sr. Negrín ${ }^{73}$.

Si únicamente se tratase de un proceso como el descrito, posiblemente no resultara demasiado complicado. Pero, como nos aporta Julià, las condiciones ante la tendencia de importar sólo lo indispensable eran complicadas. Por ejemplo tenían preferencia las organizaciones sindicales o corporativas sobre los individuos; en ocasiones, a punto de obtener un permiso solicitado, el Tesoro indica la necesidad de restringir las importaciones porque no hay divisas disponibles; si el receptor o el expedidor están acusados de no ser defensores activos y entusiastas del régimen, se les considera como sospechosos y ya no se les permite negociar... Si alguien es acusado por los comités revolucionarios, o por sus agentes en el extranjero de que alteran los precios para exportar divisas ilegalmente, no sólo les prohíben nego-

71. A 23 de Abril de 1938 el señor Julià contabiliza la población en zona republicana en 11.447.773 habitantes y la población en zona nacional en 13.064.657 habitantes. Ver Foreign Office, 371, 22670, 33.

72. Desde el país de origen y la procedencia, los contratos y precios, divisas en que han de pagarse, nombre y dirección del proveedor, justificación de que los géneros no existían en España y demás detalles. Ver Julì̀, 1938, 38 bis.

73. Ver JuliÀ, 1938, 38 bis, 4. 
ciar, sino que pueden perder la libertad y hasta la vida. En la España republicana «continúan funcionando las checas bajo control ruso y, si se recuerda que en los correos y telégrafos españoles existe la previa censura, que está siempre dispuesta a informar a los distintos departamentos antes mencionados, es fácil llegar a la conclusión de que, el secreto profesional y la seguridad del comerciante español no salen muy bien librados». En Londres se sabe algo de esto, particularmente -comenta Julià- en cuanto se refiere a la importación de minerales, frutas, tartratos y pulpa de albaricoque y en cuanto a la exportación de carbonos ${ }^{74}$. En lo relativo al comercio con otras naciones, Julià comenta que «los Estados Unidos sufren también un aparente retroceso en sus ventas a la España oficial, quedando éstas reducidas a los aceites minerales, productos químicos y comestibles, comprando sólo algunos comestibles, corcho, metales, pero directa o indirectamente, llegaron a España, materiales de guerra, aviones y camiones fabricados en los Estados Unidos, en cantidad de importancia, pero que no constan en las estadísticas» ${ }^{75}$.

El cuadro aún puede ensombrecerse más, como es de suponer bajo condiciones de una conflagración bélica, y entonces Julià añade: «las dificultades que se originan por el bloqueo de los nacionalistas, el aumento de fletes y seguros, los torpedeamientos y los ataques aéreos, que tiran al fondo del mar la mercancía tan necesitada, la escasez de buques, etc. etc.» También tuvo su efecto negativo la multiplicación de las comisiones exportadoras e importadoras, pues a las «ya existentes comisión algodonera, sedera, oficina del aceite, de combustibles, pasera, etc., se añadieron millares de comités del Frente Popular y de los sindicatos socialistas, anarquistas y comunistas que intervenían la exportación e importación, sin control oficial alguno, retirando mercancías del muelle y llevándose la documentación para evitar de ese modo tener que pagar las mercancías o, si se exportaban, tener que pagar al Gobierno las divisas correspondientes ${ }^{76}$.

La agonía económico financiera de la Segunda República española se produjo bajo condiciones extremadamente penosas, pues los años de 1936 a 1939 fueron los de nuestra Guerra Civil. A 23 de abril de 1938, según el informe del Sr. Julià, las provincias bajo el Gobierno republicano eran sólo nueve, mientras las del bando nacional más que triplicaban ese número alcanzando veintinueve,

74. Ver Julì, 1938, 38 bis, 2.

75. Ver Julià, 1938, 39 (354).

76. El Gobierno logró infiltrarse -comenta Julià- en dichos comités y los fue transformando hasta suprimir muchos de ellos. Entre los nuevos comités que sobrevivieron estaban el naranjero, el del arroz, el de la cebolla, el de la fruta seca, y el del vino, en cuanto se refiere al Ministerio de Agricultura y varios de primeras materias industriales que dependen de la Dirección General de Industria. Ver Juliè, 1938, 38 bis, 4. 
y doce provincias se encontraban en zona de guerra. La caída de la inversión extranjera dentro de la España republicana se podría considerar por consiguiente casi una tautología. En aquellas circunstancias cabía esperar probablemente sólo la decisión que a tenor del agotamiento de las reservas de oro no se hizo esperar. La República impulsó una nueva edición de la requisa «más o menos legal» de valores depositados en las cajas de alquiler de los bancos de Cataluña, que más tarde realizó también en los bancos de Valencia y del resto de España. El alcance de la incautación se estimaba en 500 millones de pesetas, que podían cubrir, según afirma el Sr. Julià $(1938,35)$, los «gastos en el extranjero hasta el mes de julio y adquirir las armas necesarias para hacer el esfuerzo final antes de capitular».

A las difíciles condiciones que se afrontaba el gobierno de Azaña, se le sumaría la depreciación de la peseta republicana en las bolsas y mercados extranjeros. Durante ese mismo tiempo aquellas penosas circunstancias dejaban el trueque para el mercado interior de la España oficial como única alternativa ante una «moneda desaparecida» ${ }^{77}$. La deducción del tipo de riesgo-país para cualquier inversor, incluidos los de las potencias que desde el final del siglo diecinueve habían asentado sus intereses en España, resulta trivial: no existía riesgo, ni probablemente tampoco país, se trataba sencillamente de pura incertidumbre con la percepción de una República en la recta final de la derrota, sin solvencia ni liquidez.

La consabida dificultad para obtener el permiso de exportación de los beneficios obtenidos por el capital extranjero, como fue el caso de la Canadian Light \& Power Company y el de la Pirelli -la primera multinacional italiana-, en 1935 ya había producido una respuesta, la de reinvertir sus ganancias en España ${ }^{78}$. Parece bastante normal que los informes del Overseas Department del banco central británico constaten la evidencia disponible, desde el siglo diecinueve hasta los años de la Segunda República: la falta de capital hizo necesaria su importación, y la apertura política precisa para permitir la implantación empresarial, en suelo español, de los intereses económicos del capital extranjero ${ }^{79}$. El problema ahora era la repatriación de las ganancias.

77. En enero de 1938: $1 £=300$ pesetas republicanas; $y$ en abril de 1938: $1 £=650$ pesetas republicanas. Ver el Informe del Sr. Julì̇, Caldetas, 1938, pp. 36-37.

78. «El capital extranjero en España ha experimentado en los últimos años -1936- muchas dificultades...». «Muchas compañías... invirtieron sus ganancias en España habida cuenta de la dificultad, en 1935, para obtener el permiso para exportar sus beneficios». Ver Draft Memorandum..., p. 8c.

79. Resulta muy sugerente e ilustrativo al respecto la aportación de Teresa ToRTelLa (2008), basada en el archivo del Banco de España. 
Los Estados Unidos aparecen a los ojos de los británicos como potencial prestamista o inversor capaz de ayudar a la nación española después del primero de abril de $1939^{80}$. Sus intereses en «utilities», es decir en inversiones en servicios públicos como carreteras, ferrocarriles, centrales eléctricas, puertos, etc., fueron relevantes porque en España, al igual que en Italia (en Italia mucho más) predominaba entre las inversiones directas americanas las de los holdings de servicios públicos. Esto era debido al número de compañías estadounidenses de telefonía y de energía eléctrica que ya operaban en España, en 1930². Las manufacturas también tuvieron cierta importancia para el inversor estadounidense, que se centraba principalmente en grupos como el del corcho, las eléctricas y la automoción. Según la estimación del US Department of Commerce (1931, 10), al final de 1930 las inversiones de capital norteamericano en España eran esencialmente inversión directa (91.480 millones de dólares), con una pequeña parte de inversiones en cartera (3.000 millones de dólares). La evolución de aquella inversión directa estadounidense entre 1936 y 1939 muestra la menor reducción, entre las experimentadas por las grandes potencias con intereses en España (ver cuadro 3.5. Inversiones extranjeras en España, 1936-1939).

Si seguimos la evolución de la inversión directa yanqui en Europa, durante la década de la Gran Depresión, daremos por aceptable y contrastada la mencionada reinversión de ganancias ante las dificultades de repatriación. Estados Unidos partía en 1929 de una posición donde las inversiones en cartera realizadas en España contrasta con las directas, por su clara apuesta a favor de estas últimas. Al mantener o incrementar sus inversiones directas en España (se constituyeron cuatro filiales US, una en 1936, otra en 1937, y dos en 1939; ver nota 60), los inversores americanos aceptaban el riesgo existente como contrapartida de los beneficios esperados y las garantías que parecía podrían brindarles los nacionales. Sin descuidar, claro está, que no parecía existir mucha más alternativa ante la falta de permisos para repatriar las ganancias obtenidas.

El desarrollo del comercio exterior norteamericano con España durante la Guerra Civil muestra la imagen de un declive dirigido hacia la extinción rápida de esas relaciones mercantiles (ver el cuadro Comercio de España con varios países, 1936-1937). Cabe deducir también que la causa principal de la ligera reducción de inversión directa estadounidense, entre 1936 y 1939, pudo deberse a pérdidas de activos sin compensar por las cifras de la reinversión de beneficios. Aunque se debe destacar, como afirma sir Arthur Salter $(1951,12)$, que la ex-

80 Y por supuesto después de ellos, es decir detrás de Gran Bretaña, como ya hemos reseñado en el extracto sacado de BEA, OV 61/3, 2170/1, p. 66.

81 Ver US Department of Commerce, 1930, p. 11. 
periencia inversora extranjera durante un período de depresión y bajos precios -a nivel internacional- resulta desalentadora y finalmente desastrosa. Esta afirmación es válida para el caso, apuntado por Salter, de las inversiones británicas en 248 compañías, cuya pérdida de valor alcanzó el 47\% entre 1928 y 1931. El caso de las inversiones norteamericanas en suelo español durante la Guerra Civil cuenta con los efectos de la depresión internacional, e incluso con la suave recesión de 1937-1938, pero el posicionamiento sectorial de las actividades en las que operaban, les permitió sobrevivir en la Península Ibérica ${ }^{82}$.

Si la Guerra Civil hizo de la repatriación de beneficios desde España un problema de difícil solución, más difícil aún parece que Estados Unidos invierta durante la segunda parte de su Gran Depresión. Sin embargo y a pesar de la mencionada recesión de 1937-1938, el flujo inversor americano es el que experimenta un menoscabo menor entre las corrientes de capital extranjero de las grandes potencias (ver cuadro: Inversiones extranjeras en España, 1936-1939). Sólo queda un nueve por ciento menos de inversión norteamericana en suelo español, cuando el capital francés, belga y británico retroceden para 1939, en porcentajes superiores, en general, al 20 por ciento, contando con el stock de capital en 1936. Este extremo corrobora la hipótesis más plausible ocurrida en toda la Europa de entreguerras para el comportamiento del capital extranjero destinado a inversiones directas: «las inversiones directas se modificaron mucho menos que aquellas realizadas por cartera o a corto plazo».

Resulta algo paradójico pero se trata de una consecuencia de la atmósfera proteccionista de los años treinta. Los controles administrativos del comercio y la transferencia de ingresos debidos a las medidas autárquicas dieron un impulso involuntario a la inversión directa en el extranjero. Por ese motivo dicha inversión directa se redujo menos, o bien aumentó más de lo que cabía esperar a primera vista (Zacchia, 1981, 181). Mucho capital extranjero, como el francés o el británico, resultaría atraído por las oportunidades en los Estados Unidos tras la devaluación del dólar de 1933, y seguiría creciendo su afluencia a ese destino por razones políticas mientras más se acercaba la Segunda Guerra Mundial.

La importancia de la inversión directa estadounidense destaca sobre las demás, ya desde mediados de los años veinte, para después quedar afectada por la Gran Depresión. Parece que la interpretación más correcta de esos hechos

82. Así lo muestra la cifra correspondiente a la inversión directa estadounidense de 1940, que recupera y sobrepasa algo el nivel alcanzado en 1929. Ver el siguiente cuadro:

Inversión directa norteamericana en España (en millones de dólares corrientes)

\begin{tabular}{|c|c|c|c|}
\hline 1929 & 1930 & 1936 & 1940 \\
\hline 72.230 & 91.480 & 80.532 & 73.396 \\
\hline
\end{tabular}

Fuente: US Census (1930, 10); (1931, 10): (1936, 9); (1940, 10). 
proviene del marco que proporcionaba el proteccionismo de entreguerras. El declive previo de aquella inversión directa US, en general, había comenzado ya desde $1929^{83}$. Veamos algunas precisiones sobre esta explicación, para lo cual observaremos, primero, el panorama de la inversión portfolio versus la de cartera y, después, comentaremos el proteccionismo y la autarquía que favorecieron el crecimiento de la inversión extranjera directa.

Con la debacle financiera de 1929 -afirma Carroll (1954, 11-12)- la fase iniciada a mediados de los veinte, cuando las inversiones americanas en el extranjero alcanzaron proporciones significativas, terminó abruptamente. El proceso fue un doloroso ajuste que sucedió sencillamente porque no sólo se pararon nuevas inversiones. Además hubo diferencia en el impacto sobre las inversiones según fueran portfolio o bien directas. Señala Carroll $(1954,13)$ la mayor dificultad para seguir el efecto de la Depresión de 1929-1931 (sic) sobre las inversiones directas en el extranjero. Brevemente, el inversor directo norteamericano esquivó la tormenta. La liquidación de sus activos fue relativamente pequeña, sencillamente porque los compradores fueron escasos, aunque se asumiera cualquier sacrificio en la venta.

Parece probable que por el año 1937 la mayor parte del daño en la orientación de la inversión extranjera norteamericana había sido reparada. Carroll $(1954,13)$ alude a los problemas de cuantificar, entonces, con métodos estadísticos más toscos que ahora, el montante de la inversión directa estadounidense en el extranjero. Para afirmar seguidamente con bastante seguridad -a pesar de esos métodos de la época- que el grueso de las inversiones directas de 1929 quedó intacto y en conjunto quedó en las mismas manos, cuando se llevó a cabo 14 años después el Censo de $1943^{84}$. Por consiguiente, la recuperación más notable de la inversión directa norteamericana se produjo en la segunda mitad de los años treinta, y se repitió la pauta de 1929 en la composición de aquellas inversiones directas de los años previos a la Segunda Guerra Mundial. En el caso español parece que, por las razones obvias de una economía de guerra, no se detecta dicho comportamiento en las inversiones directas yanquis.

83. En España, según el cuadro de la nota a pie de página anterior, a partir de 1930. Aunque ese cuadro sólo proporciona una intuición, pues no muestra las cifras en dólares constantes para que la comparación resulte más adecuada y conveniente.

84. Para las inversiones en cartera dice Carroll que sucedió lo contrario, literalmente: «In contrast, the bulk of pre-1929 portfolio investment had been largely dissipated or liquidated by the middle thirties, and little new financing of this type appeared for about two decades». Para 1939, mientras el valor del portfolio disminuyó casi por valor del agujero total de más de 4 billones de dólares (el 90\%, al menos), la inversión directa sólo se redujo en un veinteavo de su valor de 1929. Ver Carroll (1954, 13-14). 
La caída del comercio exterior y las circunstancias en que se produce permiten al Sr. Julià, en 1938, calificar a los comerciantes de héroes, habrá por tanto que dar alguna denominación similar -si resulta pertinente- a los inversores extranjeros que permanecían en su puesto. Con relación al caso más destacado, el norteamericano, se debe tener en cuenta que la inversión directa extranjera estadounidense durante el período 1929-1936 había disminuido un 10 por ciento debido a la Gran Depresión ${ }^{85}$. La necesidad en ambos casos, comerciantes e inversores, era la causa principal de su conducta económica. Si la caída en el comercio exterior de la República queda explicada por las razones aducidas más arriba, la merma de la inversión extranjera directa hunde sus raíces en el proceso global de la Gran Depresión y en la España de la dictadura de Primo de Rivera. Por supuesto, el riesgo-país asumido por las inversiones que se quedaron quedaba respaldado por el aval de las dificultades en la transferencia de las ganancias.

\section{Fuentes y Bibliografía}

\section{Fuentes}

Bank of England Archive

BEA, OV61/2, vols. 3, 4, y 5 (2169/4).

BEA, OV61/3, vols. 6, 7, 8, y 9 (2170/1).

BEA, OV61/4, vol. 10-15 (2170/2).

BEA, OV61/11.

Foreign Office

FO, 371, 22670.

FO, 371, 22685.

US Department of Commerce/Bureau of Foreign and Domestic Commerce (by Paul Dickens), American direct investment in foreign countries, Washington, 1930.

85. En el prefacio a la edición del censo de 1936, American Direct Investments in Foreign Countries se puede leer que las inversiones directas de las corporaciones americanas y de los hombres de negocios americanos en empresas y propiedades extranjeras, al final de 1936 alcanzaban 6.691.000.000 dólares, mientras que al final de 1929 la cifra era de 7.528.000.000 dólares. Ver US Department of Commerce (1938, v). 
US Department of Commerce/Bureau of Foreign and Domestic Commerce (by Paul Dickens), A new estimate of American investments abroad, Washington, 1931.

US Department of Commerce/Bureau of Foreign and Domestic Commerce (1936 by Paul Dickens), American direct investment in foreign countries, Washington, 1938.

US Department of Commerce Bureau of Foreign and Domestic Commerce (1940 by Robert L. Sammons and Milton Abelson), American direct investment in foreign countries, Washington, 1942.

US Department of Commerce, Summary of United States trade with world, 1934, Trade Information Bulletin, n. ${ }^{\circ}$ 822, Washington, 1935.

US Department of Commerce (Bureau of foreign and domestic commerce), Economic Review of Foreign Countries 1937, Economic Series, n. ${ }^{\circ}$ 2, United States Printing Office, Washington, 1938, pp. 84-85 y 89-90.

US Department of Commerce (Bureau of foreign and domestic commerce), The Balance of international payments of the United States in 1939, Economic Series, n. ${ }^{\circ}$ 8, United States Printing Office, Washington, 1940, pp. 18-29.

US Department of Commerce (Bureau of foreign and domestic commerce), Economic Review of Foreign Countries 1939 and early 1940, Economic Series, n. ${ }^{\circ}$ 9, United States Printing Office, Washington, 1941, pp. 105-110.

US Department of Commerce (Office of Business Economics), International transactions of the United States during the war, 1940-45, Economic Series, n. ${ }^{\circ} 65$, United States Government Printing Office, Washington, 1948.

World Trade Information Service, «Foreign trade of Spain, 1953-55», Statistical Reports, Part 3, n. ${ }^{\circ}$ 56-24, US Department of Commerce, 1956.

Bibliografía

Aznar Sánchez, Juan, Las inversiones extranjeras en España. Su régimen jurídico, Montecorvo, 1976.

BAjo, Óscar y TORRES, Ángel, «El comercio exterior y la inversión extranjera directa tras la integración de España en la CE (1986-90)», en Viñals, José (ed.), La economía española ante el Mercado Único europeo. Las claves del proceso de integración, Barcelona, Alianza Editorial.

Bergier, Jean-François y Jägri, André avec la collaboration de Perrenoud, Marc, Documents Diplomatiques Suisses. Diplomaische Dokumente der Schweiz, Documenti Diplomatici Svizzeri, 1848-1945, volume 13 (1939-1940), ler. janvier 1939-31 décembre 1940, Bern, Benteli Verlag, 1991.

Bourgoüin, E. y Lenoir, P., La finance internationale et la Guerre d'Espagne, París, 1938. 
Caballero Sanz, Francisco, Ortí Lahoz, Ángel y Orts Ríos, Vicente, «Direct foreign investment and internacional trade in Spain», en Yannopoulos, George N. (ed.), European integration and the Iberian economies, London, MacMillan Press, 1989, pp. 227-253.

CarReras, Albert (coord.), Estadísticas Históricas de España. Siglos XIX y XX, Madrid, Banco Exterior, 1989.

Carroll, Charles R., Private investments abroad, New York, American Enterprise Association Inc., 1954.

Catalán, Jordi, La economía española y la segunda guerra mundial, Barcelona, Ariel, 1995.

Celestino Rey, Fernando, «La administración estadística del Estado: 1936-1939», Revista Fuentes Estadísticas, 50 (enero 2001).

Comín, Francisco y Gálvez, Lina «Reglas de juego, redes de oportunidad y nacionalizaciones de empresas extranjeras durante el franquismo», en Redes de empresas en España. Una perspectiva teórica, histórica y global, Madrid, Lid Editorial Empresarial, 2005, pp. 115-136 y 201-205.

Dunning, John H., «La empresa multinacional: antecedentes», en La empresa multinacional, México, Fondo de Cultura Económica, 1976, pp. 15-56.

Dunning, John H. y NARULA, Rajneesh, «The investment development path revisited. Some emerging issues», en Foreign direct investment and governments. Catalysts for economic restructuring, London and New York, Tourtledge, 1996, pp. 1-41.

Krugman, Paul R. y ObstFeld, Maurice, Economía internacional. Teoría y política, Madrid, Pearson/Addison Wesley, 2006.

Leirz, Christian, "Nazi Germany's Intervention in the Spanish Civil War and the Foundation of HISMA/ ROWAK», en Preston, Paul y Mackenzie, Ann L. (eds.), The Republic Besieged. Civil War in Spain 1936-1939, Edinburgh, Edinburgh University Press, 1996, pp. 54-85.

LewIS, Cleona, The United States and foreign investment problems, Washington, The Brookings Institution, George Banta Publishing Company, 1948.

Martín Aceña, Pablo, «La economía de la guerra civil», Congreso de la AEHE, Santiago de Compostela, septiembre de 2005.

Martín Aceña, Pablo (ed.), La economía de la Guerra Civil, Madrid, Marcial Pons, Ediciones de Historia, 2006.

Martín Aceña, Pablo y Pons, María Ángeles, «Sistema monetario y financiero», en Estadísticas Históricas de España. Siglos XIX y XX, Bilbao, Fundación BBVA, 2005, 2. a edición revisada y ampliada, pp. 645-706.

Martínez Ruzz, Elena, «El sector exterior durante la guerra civil», Congreso de la AEHE, Santiago de Compostela, septiembre de 2005. 
Martínez Ruiz, Elena, «Las relaciones económicas internacionales: guerra, política y negocios», en Martín Aceña, Pablo (ed.), La economía de la Guerra Civil, Madrid, Marcial Pons, 2006, pp. 273-325.

Ministerio de Trabajo, Boletín de Estadística, 4 (octubre-diciembre, 1939).

Muñoz Juan, Roldán, Santiago y SerRano, Ángel, «La vía nacionalista del capitalismo español. I. Orígenes y Desarrollo (1874-1923)», Cuadernos Económicos del I.C.E., 5 (1978), pp.13-221.

Needleman, Lionel, «Comentario a los capítulos VI y VII», en Dunning, John H., La empresa multinacional, México, Fondo de Cultura Económica, 1976, pp. 269-273.

Officer, Lawrence H. y Williamson, Samuel H., «Measures of Worth. 2007», MeasuringWorth.com, 2007.

Paris Eguilaz, Higinio, Inversiones y desarrollo económico en España, Madrid, 1956.

Ruiz Morales, José Miguel, Relaciones económicas entre España y los Estados Unidos, Madrid, Ediciones Cultura Hispánica, 1945.

Sánchez Fernández, Beatriz, Proteccionismo y liberalismo. Las relaciones comerciales entre Suiza y España: 1869-1935, Frankfurt, Vervuest Verlag, 1996.

Sánchez Recio, Glicerio y Tascón, Julio (eds.), Los empresarios de Franco. Política y Economía en España, 1936-1957, Barcelona, Crítica, 2003.

TAMAMES, Ramón, Introducción a la economía española, Madrid, Alianza Editorial, 1968.

TAmames, Ramón, La República. La era de Franco, Madrid, Ediciones Alfaguara, 1981.

TASCÓN, Julio, «Internacional capital befote "capital internationalization" in Spain, 1936-1959», Center for European Studies Working Paper, Harvard University, 79 (2001), 28 pp.

TAsCón, Julio, La inversión directa norteamericana en España, 1929-1964, mímeo, 2005.

TASCón, Julio y Carreras, Albert, «Investissements étrangers et intérêts suisses en Espagne (1936-1946)», en La Suisse et l'Espagne. De la République à Franco (1936-1946), Lausanne, Éditions Antipodes, 2001.

Tena Junguito, Antonio, «Las estadísticas históricas del comercio internacional: fiabilidad y comparabilidad (1890-1960)», Estudios de Historia Económica, Madrid, 24 (1992), Imprenta del Banco de España.

TorTelLa, Teresa, Una Guía de fuentes sobre inversiones extranjeras en España (17801914), Madrid, Archivo del Banco de España, 2000.

Viñas, Ángel, Guerra, Dinero, Dictadura. Ayuda fascista y autarquía en la España de Franco, Barcelona, Editorial Crítica, 1984. 
Viñas, Ángel, La soledad de la República. El abandono de las democracias y el viraje hacia la Unión Soviética, Barcelona, Crítica, 2006.

Viñas, Ángel, El escudo de la República. El oro de España, la apuesta soviética y los hechos de mayo de 1937, Barcelona, Crítica, 2007.

Viñas, Ángel, Viñuela, Julio, Eguidazu, Fernando, Fernández Pulgar, Carlos y FloRENSA, Senén, Política Comercial Exterior en España (1931-1975), t. 1, Madrid, Banco Exterior de España, Servicio de Estudios Económicos, 1979.

Yannopoulos, George N. (ed.), European integration and the Iberian economies, London, MacMillan Press, 1989.

ZACCHIA, Carlo, «Comercio internacional y movimientos de capital 1920-1970», en Cipolla, Carlo M. (ed.), Historia Económica de Europa. Siglo XX. Segunda parte, Barcelona, Ariel, 1981, pp. 113-206. 